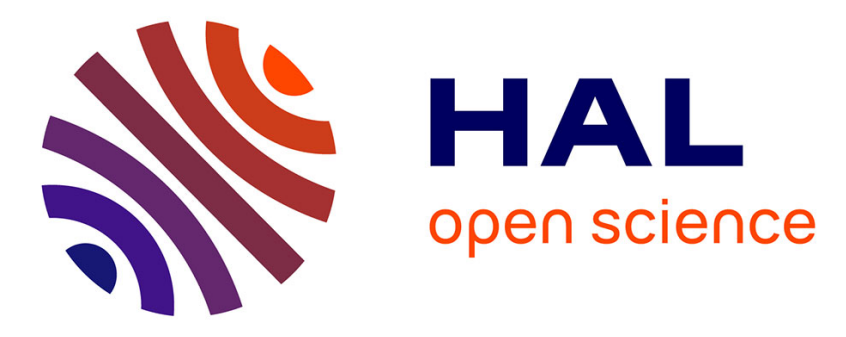

\title{
Drug-Initiated Synthesis of Heterotelechelic Polymer Prodrug Nanoparticles for In Vivo Imaging and Cancer Cell Targeting
}

Daniele Vinciguerra, Anna Degrassi, Laura Mancini, Simona Mura, Julie Mougin, Patrick Couvreur, Julien Nicolas

\section{To cite this version:}

Daniele Vinciguerra, Anna Degrassi, Laura Mancini, Simona Mura, Julie Mougin, et al.. DrugInitiated Synthesis of Heterotelechelic Polymer Prodrug Nanoparticles for In Vivo Imaging and Cancer Cell Targeting. Biomacromolecules, 2019, 20 (7), pp.2464-2476. 10.1021/acs.biomac.9b00148 . hal02323838

\section{HAL Id: hal-02323838 \\ https://hal.science/hal-02323838}

Submitted on 21 Oct 2019

HAL is a multi-disciplinary open access archive for the deposit and dissemination of scientific research documents, whether they are published or not. The documents may come from teaching and research institutions in France or abroad, or from public or private research centers.
L'archive ouverte pluridisciplinaire HAL, est destinée au dépôt et à la diffusion de documents scientifiques de niveau recherche, publiés ou non, émanant des établissements d'enseignement et de recherche français ou étrangers, des laboratoires publics ou privés. 


\section{Drug-Initiated Synthesis of Heterotelechelic Polymer}

\section{Prodrug Nanoparticles for In Vivo Imaging and}

\section{Cancer Cell Targeting}

Daniele Vinciguerra, ${ }^{1}$ Anna Degrassi, ${ }^{2}$ Laura Mancini, ${ }^{2}$ Simona Mura, ${ }^{1}$ Julie Mougin,,${ }^{1}$ Patrick Couvreur, ${ }^{1}$ Julien Nicolas ${ }^{1, *}$

${ }^{1}$ Institut Galien Paris-Sud, UMR CNRS 8612, Univ Paris-Sud, Faculté de Pharmacie, 5 rue JeanBaptiste Clément, F-92296 Châtenay-Malabry cedex, France.

${ }^{2}$ Biology Department, Nerviano Medical Sciences, via Pasteur 10, 20014 Nerviano MI, Italy

*To whom correspondence should be addressed.

Email: julien.nicolas@u-psud.fr

Tel.: +33146835853

Twitter: @julnicolas 


\begin{abstract}
"Drug-initiated" nitroxide-mediated synthesis of two well-defined, heterotelechelic polymer prodrugs $\left(M_{\mathrm{n}}=1960-5260 \mathrm{~g} \cdot \mathrm{mol}^{-1}, Ð=1.31-1.37\right)$ was performed by using the newly-developed nitroxide exchange reaction. These polymers comprised at the chain-end, gemcitabine (Gem) as anticancer drug and either cyanine 7.5 (Cy7.5) as a near-infrared (NIR) dye suitable for in vivo imaging, or biotin (Biot) for cancer cell targeting. These materials were co-nanoprecipitated into fluorescently-labeled polymer prodrug nanoparticles of average diameter in the 100-180 nm with narrow particle size distribution and variable surface amounts of biotin. Nanoparticles containing 15 wt.\% biotinylated polymer showed superior uptake and the highest cytotoxicity in vitro on A549 human lung cancer cells. In vivo, on A549 tumor bearing mice, biotinylated nanoparticles showed significantly higher efficacy than free Gem and maintained the same anticancer activity than nontargeted nanoparticles without inducing prohibitive body weight loss. Biotinylated polymer prodrug nanoparticles did not result in an improved anticancer activity or significant increase in tumor accumulation, which may be the result of either a not optimal biotin surface display and/or insufficient affinity towards the target. They however displayed delayed liver accumulation compared to non-biotinylated counterparts, suggesting premise of stealth property likely due to the hydrophilic tetraethyleneglycol-Biot positioned at the nanoparticle surface. This work showed for the first time the applicability of this simple construction method to in vivo imaging and cancer cell targeting, and might stimulate the design of new functional materials for biomedical applications.
\end{abstract}

\title{
Keywords
}

Polymer, nanoparticles, prodrug, cancer, imaging 


\section{Introduction}

Recent advances in anticancer therapy showcased nanomedicines as potentially powerful tools to overcome several issues associated with conventional chemotherapy, such as early metabolization, rapid excretion and nonspecific biodistribution of conventional drugs. ${ }^{1,2}$ The most widely used approach is the physical encapsulation of drugs into nanocarriers (e.g., micelles, ${ }^{3}$ liposomes, ${ }^{4}$ polymer nanoparticles ${ }^{5}$ ), which resulted in a wide array of promising achievement and advanced clinical trials. ${ }^{6,7}$ Among the different systems, polymers offer notable advantages such as high flexibility resulting from potent macromolecular synthetic strategies, great diversity in terms of nature, properties and compositions, and easiness of functionalization. ${ }^{8}$ Nonetheless, for successful translation to the clinical stage, nanomedicines still need to address important limitations, most notably: (i) rather poor drug loadings (DL), which necessitate high concentration of nanocarriers that may lead to in vivo toxicity and (ii) the "burst release", which is the rapid and uncontrolled release of drugs post-administration. The prodrug approach, ${ }^{9}$ relying on the covalent linkage between the drug and the polymer scaffold, appeared to be a smart way to overcome those limitations. The most employed technique to prepare polymer prodrugs, the so-called "grafting to" approach, consists in coupling a drug to a preformed polymer, such as poly( $N$-(2-hydroxypropyl) methacrylamide) $(\text { HPMA })^{10-13}$ or many others. ${ }^{9}$ However, this strategy may appear somewhat complex as it often resulted in multistep syntheses and tedious purification, and still exhibits rather moderate DL. In recent years, the "drug-initiated method" $" 14$ was proposed as an alternative to tackle these issues. It consists in growing a polymer chain in a controlled manner from a drug-bearing initiator and showed several key advantages over other construction methodologies: (i) a few synthetic steps with high yields and facilitated purification; (ii) a quantitative incorporation of one drug molecule at the extremity of each polymer chain; (iii) a tunable drug loading that can reach high values (up to $40 \mathrm{wt} . \%$ ) by reduction of the polymer chain length and (iv) its applicability to virtually any kind of polymer and drug, providing the latter can be functionalized. The "druginitiated method" has been performed by reversible-deactivation radical polymerization (RDRP), 
especially reversible addition-fragmentation chain transfer (RAFT) polymerization ${ }^{15}$ and nitroxidemediated polymerization (NMP), ${ }^{16}$ leading to well-defined polymer prodrugs from different drug/polymer pairs. ${ }^{17-25}$ The resulting polymer prodrug nanoparticles exhibited high DL, high colloidal stability without any additional surfactant, significant in vitro cytotoxicity against various cancer cell lines and ability to drastically reduce tumor growth in vivo.

Another important advantage provided by RDRP techniques is the nearly quantitative retention of the controlling agent (i.e., nitroxide for NMP and chain transfer agent for RAFT polymerization) at the $\omega$-chain end, whose presence can be capitalized on to further postfunctionalize the polymer with a second biological moiety. Such telechelic polymers are gaining broad importance in the biomedical field ${ }^{26}$ and we recently proposed a simple synthetic strategy to synthesize heterotelechelic polymer prodrugs by combining the "drug-initiated method" and the nitroxide exchange reaction, to position either a drug and UV-Vis fluorescent probe for in vitro imaging or two different drugs for combination therapy. ${ }^{27,28}$

Despite these recent achievements, ability for this new type of nanomedicine to specifically target cancer cells ${ }^{29}$ and/or to enable in vivo imaging is crucially lacking. ${ }^{14}$ Such a demonstration would certainly provide additional key benefits and flexibility to the "drug-initiated" approach. Whereas in vivo imaging allows biodistribution and semi-quantitative appreciation of pharmacokinetics of polymer nanoparticles to be determined, ${ }^{30-33}$ their surface functionalization with biologically active ligands is recognized as a promising way to promote their selective internalization by cancer cells via a receptor-mediated mechanism, thus increasing therapeutic benefits and limiting undesired systemic side effects. ${ }^{8}$

In this view, we report on the implementation and investigation of both features in the "drug-initiated" approach via the development of targeted, fluorescent polymer prodrug nanoparticles resulting from the co-nanoprecipitation of two different heterotelechelic polymer prodrugs, bearing either a drug and a near-infrared (NIR) dye suitable for in vivo imaging, or a drug and biotin as a model ligand for cancer cell targeting (Figure 1). Because we wanted to keep this 
system as simple as possible and keep the DL as high as possible, another aim of this study was to determine whether simple surface-functionalization with biotin of nanoparticles prepared by the "drug-initiated" method was enough to induce an efficient targeting compared to the traditional construction approach consisting in positioning the targeting ligand at the surface of PEGylated nanoparticles.
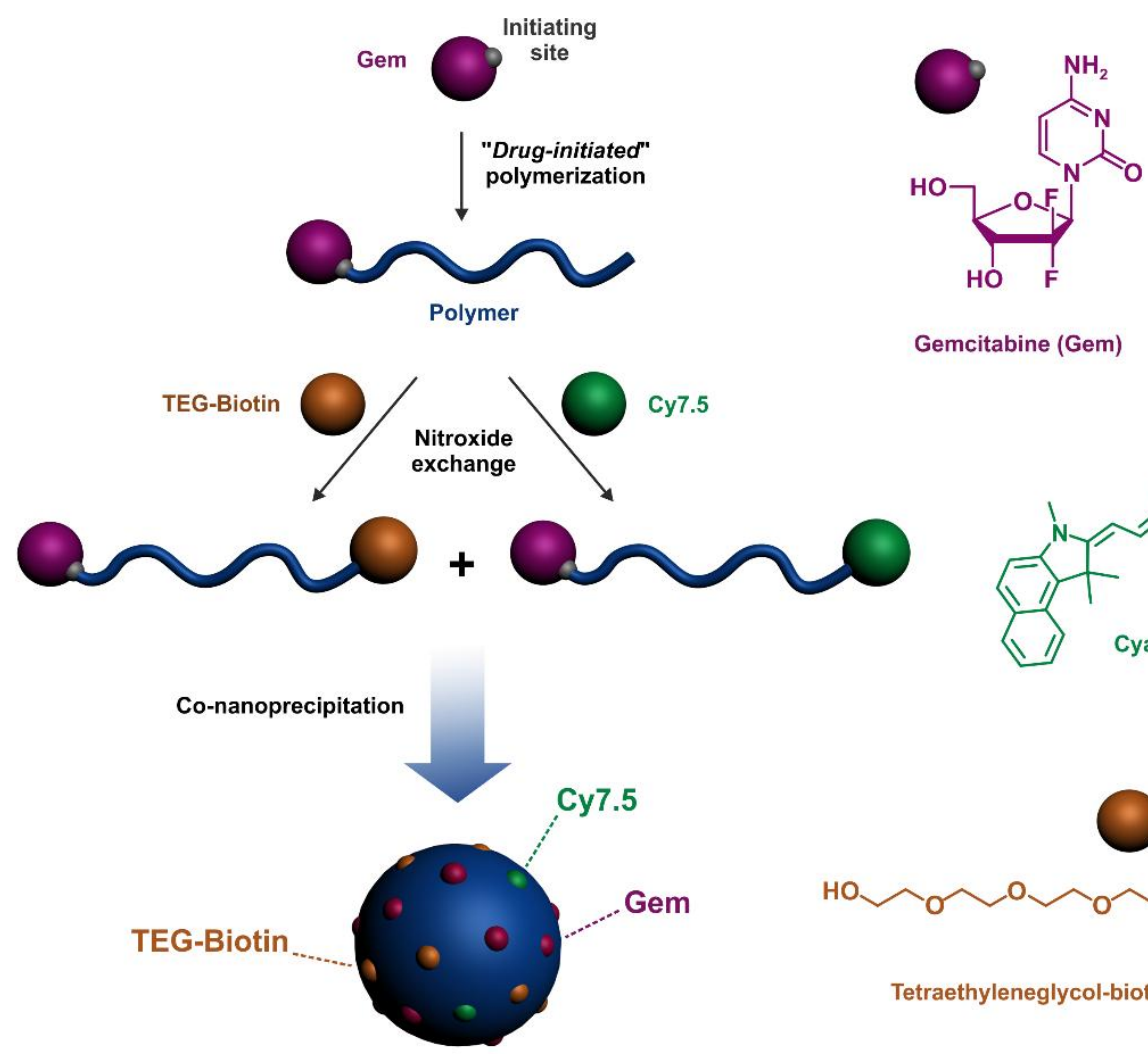

Gemcitabine (Gem)

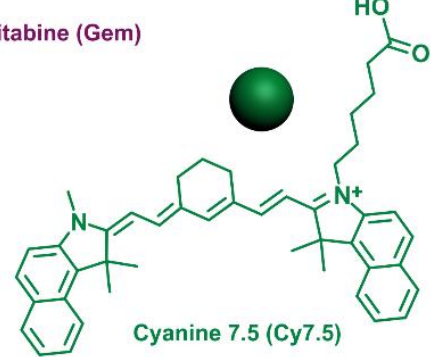

Figure 1. "Drug-initiated" synthesis of heterobifunctional polymer prodrug nanoparticles by conanoprecipitation of heterobifunctional polymers bearing: (i) gemcitabine (Gem) and cyanine 7.5 (Cy7.5) or (ii) Gem and tetraethyleneglycol-biotin (TEG-Biot).

\section{Materials and Methods}

\subsection{Materials}

Gemcitabine (> 98\%) was obtained from Carbosynth Limited (UK). Benzotriazol-1yloxytripyrrolidinophosphonium hexafluorophosphate (PyBOP), EDC $\mathrm{HCl}, \quad N, N-$ 
diisopropylethylamine (DIPEA), isoprene, 4-(dimethylamino)pyridine (DMAP), 4-carboxyTEMPO, 4-amino-TEMPO, biotin (Biot), tetraethyleneglycol (TEG), tetrahydrouridine and human serum (H4522) were purchased from Sigma-Aldrich (France) and used as received. Cyanine7.5 NHS ester was purchased from Lumiprobe (Germany). AMA-SG1, ${ }^{34}$ Gem-AMA-SG1, ${ }^{17}$ Gem-PIRho, ${ }^{27}$ Gem-PI-SG1 (Gem-PI, Gem-PI') ${ }^{28}$ and PI-SG1 (PI) ${ }^{27,28}$ were prepared as described elsewhere. All other reactants were purchased from Sigma-Aldrich at the highest available purity and used as received. Deuterated chloroform $\left(\mathrm{CDCl}_{3}\right)$ was purchased from Eurisotop. Dulbecco's Phosphate-Buffered Saline (PBS, pH 7.2-7.4) was purchased from ThermoFisher Scientific. All other solvents were purchased from Carlo-Erba at the highest grade. Roswell Park Memorial Institute (RPMI) 1640 medium was obtained from Gibco (Italy). Fetal bovine serum (FBS) was purchased from EuroClone (Italy). N-tert-butyl- $N$-(1-diethylphosphono-2,2-dimethylpropyl) nitroxide (SG1, 85\%) was kindly supplied by Arkema.

\subsection{Analytical methods}

Nuclear magnetic resonance (NMR) spectroscopy. NMR spectroscopy was performed in $5 \mathrm{~mm}$ diameter tubes in $\mathrm{CDCl}_{3}$ at $25{ }^{\circ} \mathrm{C} .{ }^{1} \mathrm{H}$ and ${ }^{13} \mathrm{C}$ NMR spectroscopy was performed on a Bruker Avance 300 spectrometer at $300 \mathrm{MHz}\left({ }^{1} \mathrm{H}\right)$ and $75 \mathrm{MHz}\left({ }^{13} \mathrm{C}\right)$, respectively. The chemical shift scale was calibrated based on the internal solvent signals. For nitroxide derivative characterization, pentafluoruphenylhydrazine was added in situ and allowed to react before the analysis. ${ }^{35,36}$

Mass spectrometry. Mass spectra were recorded with a Bruker Esquire-LC instrument. Highresolution mass spectra (ESI) were recorded on an ESI/TOF (LCT, Waters) LC-spectrometer.

Size exclusion chromatography (SEC). SEC was performed with two columns from Polymer Laboratories (PL-gel MIXED-D; $300 \times 7.5 \mathrm{~mm}$; bead diameter $5 \mathrm{~mm}$; linear part 400 to $4 \times 10^{5}$ g. $\mathrm{mol}^{-1}$ ), a differential refractive index detector (Spectra System RI-150 from Thermo Electron Corp.). The eluent was chloroform at $30{ }^{\circ} \mathrm{C}$ and at a flow rate of $1 \mathrm{~mL} \cdot \mathrm{min}^{-1}$ (Waters 515 pump). Toluene was used as a flow-rate marker. The calibration curve was based on polystyrene (PS) 
standards (peak molar masses, $M_{\mathrm{p}}=162-523000$ g.mol ${ }^{-1}$ ) from Polymer Laboratories. A polyisoprene (PI) calibration curve was constructed by converting the PS standard peak molecular weights $\left(M_{\mathrm{PS}}\right)$ to PI molecular weights $\left(M_{\mathrm{PI}}\right)$ using Mark-Houwink-Sakurada (MHS) constants determined for both polymers in $\mathrm{CCl}_{4}$ at $25^{\circ} \mathrm{C}$. For PI, the MHS constants used were $K_{\mathrm{PI}}=2.44 \times$ $10^{4}$ and $\alpha_{\mathrm{PI}}=0.712$. For PS, $K_{\mathrm{PS}}=7.1 \times 10^{4}$ and $\alpha_{\mathrm{PS}}=0.54\left(M_{\mathrm{w}}<16700 \mathrm{~g} \cdot \mathrm{mol}^{-1}\right)$ or $K_{\mathrm{PS}}=1.44 \times$ $10^{4}$ and $\alpha_{\mathrm{PS}}=0.713\left(M_{\mathrm{w}}>16700 \mathrm{~g} \cdot \mathrm{mol}^{-1}\right) .{ }^{17}$ This technique allowed the calculation of the numberaverage molar mass $\left(M_{\mathrm{n}}\right)$, the weight-average molar mass $\left(M_{\mathrm{w}}\right)$ and the dispersity $\left(M_{\mathrm{w}} / M_{\mathrm{n}}, Ð\right)$.

Dynamic light scattering (DLS) and zeta potential. Intensity-averaged nanoparticle diameters $(D z)$ and zeta potentials $(\zeta)$ were measured by dynamic light scattering (DLS) with a Nano ZS from Malvern $\left(173^{\circ}\right.$ scattering angle) at a temperature of $25^{\circ} \mathrm{C}$. The surface charge of the nanoparticles was investigated by $\zeta$-potential $(\mathrm{mV})$ measurement at $25{ }^{\circ} \mathrm{C}$ after dilution with $1 \mathrm{mM} \mathrm{NaCl}$, using the Smoluchowski equation.

Cryogenic transmission electron microscopy (cryo-TEM). $5 \mu \mathrm{L}$ of the nanoparticle suspension (0.5 mg.mL $\mathrm{m}^{-1}$ ) was deposited on a Lacey Formvar/carbon 300 mesh copper microscopy grid (Ted Pella). Most of the drop was removed with a blotting filter paper and the residual thin film remaining within the holes was vitrified by plunging into liquid ethane. Samples were then observed using a JEOL 2100HC microscope.

\subsection{Synthesis}

Synthesis of Biot-TEG (2-(2-(2-(2-hydroxyethoxy)ethoxy)ethoxy)ethyl 5-(2-oxohexahydro-1Hthieno[3,4-d]imidazol-4-yl)pentanoate). After $15 \mathrm{~min}$ of stirring, a solution of biotin $(0.500 \mathrm{~g}$, $2.05 \mathrm{mmol}), \mathrm{EDC}(0.470 \mathrm{~g}, 2.46 \mathrm{mmol}), \mathrm{DMAP}$ (cat) in DCM (25 mL) was added dropwise to a solution of TEG (3.96 g, $20.5 \mathrm{mmol})$ in DCM (25 mL). The solution was stirred overnight under argon at room temperature. The volatiles were evaporated and the crude product was purified by flash chromatography $\left(\mathrm{SiO}_{2}, \mathrm{DCM}: \mathrm{MeOH}, 9: 1, \mathrm{v}: \mathrm{v}\right)$ to give $0.754 \mathrm{~g}$ of biotin-TEG, as an oil. Yield $=87 \% .{ }^{1} \mathrm{H}$ NMR $\left(300 \mathrm{MHz}, \mathrm{CDCl}_{3}\right): \delta 5.98(\mathrm{~s}, 1 \mathrm{H}), 5.32(\mathrm{~s}, 1 \mathrm{H}), 4.59-4.46(\mathrm{t}, 1 \mathrm{H}), 4.33(\mathrm{t}, 1 \mathrm{H})$, 
$4.24(\mathrm{q}, 2 \mathrm{H}), 3.81-3.57(\mathrm{~m}, 14 \mathrm{H}), 3.23-3.08(\mathrm{~m}, 2 \mathrm{H}), 2.92(\mathrm{dd}, 1 \mathrm{H}), 2.76(\mathrm{~d}, 1 \mathrm{H}), 2.39(\mathrm{t}, 2 \mathrm{H})$, $1.66(\mathrm{~s}, 4 \mathrm{H}), 1.48(\mathrm{dd}, 2 \mathrm{H}) . \mathrm{MS}(\mathrm{ESI}+): \mathrm{m} / \mathrm{z}=443.3(\mathrm{M}+\mathrm{Na})^{+}$. Calc. for $\mathrm{C}_{18} \mathrm{H}_{32} \mathrm{~N}_{2} \mathrm{O}_{7} \mathrm{~S}: 420.19$.

Synthesis of TEMPO-Biot. After $15 \mathrm{~min}$ of stirring, a solution of 4-carboxy-TEMPO (0.342 g, $1.71 \mathrm{mmol}), \mathrm{EDC}(0.328 \mathrm{~g}, 1.71 \mathrm{mmol}), \mathrm{DMAP}(0.017 \mathrm{~g}, 0.143 \mathrm{mmol})$ in DCM (5 mL) was added dropwise to a solution of biotin-TEG $(0.600 \mathrm{~g}, 1.43 \mathrm{mmol})$ in DCM $(5 \mathrm{~mL})$. The solution was stirred overnight under argon at room temperature. Water was added $(50 \mathrm{~mL})$ and then extracted three times with DCM. The combined organic layers were washed with brine, dried over $\mathrm{MgSO}_{4}$ and concentrated under reduced pressure. After purification by flash chromatography $\left(\mathrm{SiO}_{2}\right.$, DCM:MeOH, 95:5, v:v), $0.512 \mathrm{~g}$ of TEMPO-Biot were obtained as a red-orange oil. Yield: $65 \% .{ }^{1} \mathrm{H}$ NMR $\left(300 \mathrm{MHz}, \mathrm{CDCl}_{3}\right): \delta 5.84(\mathrm{~s}, 1 \mathrm{H}), 5.35(\mathrm{~s}, 1 \mathrm{H}), 4.56-4.47(\mathrm{t}, 1 \mathrm{H}), 4.33(\mathrm{t}, 1 \mathrm{H}), 4.23(\mathrm{~m}$, 4H), $3.76-3.58(\mathrm{~m}, 12 \mathrm{H}), 3.16(\mathrm{~m}, 1 \mathrm{H}), 2.93(\mathrm{dd}, 1 \mathrm{H}), 2.74(\mathrm{~d}, 1 \mathrm{H}), 2.68(\mathrm{~m}, 1 \mathrm{H}), 2.37(\mathrm{t}, 2 \mathrm{H})$, $1.85(\mathrm{~d}, 2 \mathrm{H}), 1.70(\mathrm{~m}, 6 \mathrm{H}), 1.54-1.42(\mathrm{~m}, 2 \mathrm{H}), 1.33-1.07(\mathrm{~m}, 12 \mathrm{H}) \cdot \mathrm{MS}(\mathrm{ESI}+): \mathrm{m} / \mathrm{z}=625.8$ $(\mathrm{M}+\mathrm{Na})^{+}$. Calc. for $\mathrm{C}_{40} \mathrm{H}_{49} \mathrm{~N}_{2} \mathrm{O}_{16}: 602.31$.

Synthesis of Gem-PI-Biot. In a 7-mL vial were dissolved Gem-PI-SG1 (Gem-PI, 300 mg, 1 eq) and TEMPO-Biot (1 eq) in dry pyridine $(1 \mathrm{~mL})$. The solution was degassed under argon for $20 \mathrm{~min}$ before placing the vial in a preheated oil bath at $110{ }^{\circ} \mathrm{C}$ and stirring for $16 \mathrm{~h}$. Gem-PI-Biot was then precipitated two times in cold methanol and dried under reduced pressure. The purified polymer was characterized by SEC. The post-functionalization yield was calculated by ${ }^{1} \mathrm{H}$ NMR using the following chemical shifts of Biot $(\delta=4.56-4.47,4.33,4.23,3.76-3.58,3.16$ and $2.93 \mathrm{ppm})$ and the chemical shifts of aromatic and anomeric proton of $\operatorname{Gem}(\delta=8.26,7.48$ and $6.26 \mathrm{ppm})$.

Synthesis of TEMPO-Cy7.5. To a solution of 4-amino-TEMPO (0.033 g, $0.192 \mathrm{mmol})$ and cyanine7.5 NHS ester $(0.100 \mathrm{~g}, 0.128 \mathrm{mmol})$ in dry DCM $(7 \mathrm{~mL})$ was added DIPEA $(0.11 \mathrm{~mL}$, $0.639 \mathrm{mmol}$ ) by syringe under argon atmosphere. The reaction was stirred overnight, in the dark under argon at room temperature. Water was added $(50 \mathrm{~mL})$ and then extracted three times with DCM. The combined organic layers were washed with brine, dried over $\mathrm{MgSO}_{4}$ and concentrated under reduced pressure. After purification by flash chromatography ( $\left.\mathrm{SiO}_{2}, \mathrm{DCM}: \mathrm{MeOH}, 96: 4, \mathrm{v}: \mathrm{v}\right)$, 
$0.080 \mathrm{~g}$ of TEMPO-Cy7.5 were obtained as a green-blue solid. Yield: $86 \% .{ }^{1} \mathrm{H}$ NMR (300 MHz, $\left.\mathrm{CDCl}_{3}\right): \delta 8.11(\mathrm{~d}, 2 \mathrm{H}), 7.92(\mathrm{~m}, 4 \mathrm{H}), 7.75(\mathrm{~m}, 2 \mathrm{H}), 7.59(\mathrm{t}, 2 \mathrm{H}), 7.53-7.31(\mathrm{~m}, 5 \mathrm{H}), 6.22-5.92$ (m, 2H), $4.19(\mathrm{~m}, 2 \mathrm{H}), 3.69(\mathrm{~s}, 3 \mathrm{H}), 3.64(\mathrm{~m}, 1 \mathrm{H}), 2.60(\mathrm{~m}, 4 \mathrm{H}), 2.32(\mathrm{t}, 2 \mathrm{H}), 2.00(\mathrm{~d}, 12 \mathrm{H}), 1.67$ (m, 14H), $1.32(\mathrm{~d}, 12 \mathrm{H})$. MS (ESI+): $\mathrm{m} / \mathrm{z}=802.5(\mathrm{M})^{+}$. Calc. for $\mathrm{C}_{54} \mathrm{H}_{66} \mathrm{~N}_{4} \mathrm{O}_{2}: 802.5$.

Synthesis of Gem-PI-Cy7.5. Briefly, in a 7-mL vial were dissolved Gem-PI-SG1 (Gem-PI', 300 $\mathrm{mg}, 1 \mathrm{eq})$ and TEMPO-Cy7.5 (1 eq) in dry pyridine $(1 \mathrm{~mL})$. The solution was degassed under argon for 20 min before placing the vial in a preheated oil bath at $110{ }^{\circ} \mathrm{C}$ and stirring for $16 \mathrm{~h}$. Gem-PICy7.5 was then precipitated two times in cold methanol and dried under reduced pressure. The purified polymer was characterized by SEC and ${ }^{1} \mathrm{H}$ NMR. The post-functionalization yield was calculated by ${ }^{1} \mathrm{H}$ NMR using the chemical shifts of aromatic protons of Cy7.5 $(\delta=8.16-7.32 \mathrm{ppm})$ and the chemical shifts of anomeric proton of Gem $(\delta=6.39 \mathrm{ppm})$.

\subsection{Nanoparticle preparation}

All nanoparticles were prepared by the nanoprecipitation technique at a concentration of 2.5 mg.mL $\mathrm{m}^{-1} \cdot{ }^{37}$ Multifunctional nanoparticles for in vivo imaging were prepared by co-nanoprecipitation of Gem-PI-Biot (variable), Gem-PI (variable) and Gem-PI-Cy7 (fixed at 10 wt.\%) as follows: N0 = 0:90:10, N15 $=$ 15:75:10, N50 $=$ 50:40:10 and N90 = 90:0:10 (in wt.\%), respectively. Similarly, multifunctional nanoparticles for internalization experiment were prepared by co-nanoprecipitation of Gem-PI-Biot (variable), Gem-PI (variable) and Gem-PI-Rho (fixed at 10 wt. $\%)^{28}$ as follows: N0* $=$ 0:90:10, N15* $=15: 75: 10, \mathbf{N 5 0} *=50: 40: 10$ and N90* $=90: 0: 10$ (in wt.\%), respectively. Bare PI or monofunctional Gem-PI nanoparticles were prepared from the corresponding polymers. Briefly, $2.5 \mathrm{mg}$ of PI or Gem-PI were dissolved in $0.5 \mathrm{~mL}$ of THF and quickly added to $1 \mathrm{~mL}$ of MilliQ water. THF was evaporated at ambient temperature using a Rotavapor. Intensity-averaged diameter $\left(D_{\mathrm{z}}\right)$ and zeta potential measurements were carried out in triplicate by DLS. The nanoparticle colloidal stability was assessed in water for 55 days. The nanoparticles were kept at $4^{\circ} \mathrm{C}$ and allowed to reach room temperature before each measurement. For in vivo experiment, nanoparticles 
were concentrated at ambient temperature using a Rotavapor and then adjusted to the right concentration by addition of water.

\subsection{Gemcitabine release}

The Gem release kinetics was determined as follows. $0.2 \mathrm{~mL}$ of nanoparticle suspension (N90) were added to $800 \mu \mathrm{L}$ of human serum supplemented with $200 \mu \mathrm{g} \cdot \mathrm{mL}^{-1}$ tetrahydrouridine (THU). ${ }^{38,39}$ The mixture was aliquoted $(100 \mu \mathrm{L})$, incubated at $37{ }^{\circ} \mathrm{C}$ and each aliquot withdrawn at different time points $(1,2,4,8$ and $24 \mathrm{~h})$. The different samples were spiked with $10 \mu \mathrm{L}$ of $10 \mu \mathrm{M}$ theophylline (Internal Standard, IS) before addition of $1 \mathrm{~mL}$ of a mixture of acetonitrile:methanol (90:10, v:v) and ultracentrifugated $\left(15000 \mathrm{~g}, 20 \mathrm{~min}, 4{ }^{\circ} \mathrm{C}\right)$. The supernatant was then evaporated to dryness under a nitrogen flow at $30{ }^{\circ} \mathrm{C}$ and the released drug was quantified by reverse-phase HPLC following the method described in our previous publication. ${ }^{28}$

A similar experiment was conducted in the presence of Cathepsin B. $140 \mu \mathrm{L}$ of nanoparticle suspension (N90) were added to $560 \mu \mathrm{L}$ of human serum supplemented with $200 \mu \mathrm{g} \cdot \mathrm{mL}^{-1} \mathrm{THU}$. The mixture was spiked with $2.5 \mu \mathrm{L}$ of a Cathepsin B solution $\left(1000 \mathrm{U} \cdot \mathrm{mL}^{-1}\right)$, added at $\mathrm{t}=0$ and 8 h. The mixture was aliquoted $(100 \mu \mathrm{L})$, incubated at $37^{\circ} \mathrm{C}$ and each aliquot withdrawn at different time points $(0,1,8,24 \mathrm{~h})$. The different samples were spiked with $10 \mu \mathrm{L}$ of $10 \mu \mathrm{M}$ theophylline (Internal Standard) before addition of $1 \mathrm{~mL}$ of a mixture of acetonitrile:methanol (90:10, v:v) and ultracentrifuged $\left(15000 \mathrm{~g}, 20 \mathrm{~min}, 4^{\circ} \mathrm{C}\right)$. The supernatant was then evaporated to dryness under a nitrogen flow at $30^{\circ} \mathrm{C}$. The HPLC analysis was performed under identical experimental conditions as described previously.

\subsection{Cell lines and cell culture}

Human lung cancer cell line A549 was obtained from the American Type Culture Collection (ATCC) and maintained as recommended. Briefly, A549 cells were grown in Roswell Park 
Memorial Institute (RPMI) 1640 medium. Medium was supplemented with 10\% FBS and 2 mM Lglutamine. Cells were maintained in a humid atmosphere at $37{ }^{\circ} \mathrm{C}$ with $5 \% \mathrm{CO}_{2}$.

\subsection{Fluorescence-activated cell sorting (FACS)}

Uptake of targeted nanoparticles by cancer cells was assessed by flow cytometry. A549 cells $(1 \times$ $10^{5}$ per well) were seeded in 12 -well plates $(1 \mathrm{~mL}$ per well). After $24 \mathrm{~h}$, cells were treated with 25 $\mu \mathrm{g} . \mathrm{mL}^{-1}$ of nanoparticles (N0* $\mathbf{N 1 5}^{*}, \mathbf{N 5 0} *$ and N90*) containing 10 wt.\% of Gem-PI-Rho, and a variable percentage of Gem-PI-Biot. Plates were maintained at $37^{\circ} \mathrm{C}$ for 6 or $24 \mathrm{~h}$, or at $4{ }^{\circ} \mathrm{C}$ for 6 h. Afterwards, cells were detached with trypsin/EDTA then washed 3 times with PBS $+0.02 \%$ BSA $(1 \mathrm{~mL})$, transferred in FACS tubes and run on a BD FACS Aria (BD Biosciences) flow cytometer equipped with 488 (excitation) and 633 (emission) nm laser, acquiring 10000 events gating out debris and aggregates. Median Fluorescence Intensity (M.F.I.) of each sample was recorded. All experiments were repeated independently at least two times (4 replicates per condition each) to determine means and SDs. ANOVA two-way with Tukey's correction post-test was used to determine statistical differences.

\subsection{In vitro cytotoxicity}

To evaluate the antiproliferative activity of the different compounds tested, cells $\left(4 \times 10^{3}\right.$ per well $)$ were seeded in 96- well plates. $24 \mathrm{~h}$ after seeding, the medium was replaced with medium containing serial dilutions of polymer prodrug nanoparticles, control polymers or free drugs for 72 h. Cell viability was assessed using the CellTiter- Glo luciferase- based ATP detection assay (Promega) following manufacturer's instructions. CellTiter- Glo is a homogeneous assay method based on the quantification of ATP, an indicator of the number of metabolically active cells. Growth inhibitory activity was evaluated at the end of incubation, comparing data for treated versus control samples, using Accelrys ${ }^{\circledR}$ Assay Explorer software. The inhibitory concentration 50\% $\left(\mathrm{IC}_{50}\right)$ of the treatments was determined from the dose-response curve. All experiments were 
repeated independently at least two times (4 replicates per condition each) to determine means and SDs.

\subsection{Animal care and tumor induction}

Six-week-old male athymic CD1 nude mice were purchased from Charles River Italia. All animals were housed in appropriate animal care facilities during the experimental period and were handled according to the principles of laboratory animal care and legislation in force in Italy $\left(\mathrm{n}^{\circ} 1201 / 2016-\right.$ PR). $200 \mu \mathrm{L}$ of the $\mathrm{A} 549$ cell suspension, equivalent to $5 \times 10^{6}$ cells, were subcutaneously injected into nude mice toward the lower portion of the right flank. Tumors were allowed to grow for 20 days to a volume of at least $100 \mathrm{~mm}^{3}$ before initiating the treatment. Tumor length and width were measured with calipers, and the tumor volume was calculated using the following equation: $\mathrm{V}_{\text {tumor }}=$ $\left(\right.$ length $\times$ width $\left.^{2}\right) / 2$.

\subsection{In vivo anticancer activity on solid tumor-bearing mice}

Tumor-bearing nude mice were randomly divided into 4 groups of 8 each and all groups received five intravenous injections on days $0,4,7,11$ and 14 in the lateral tail vein. On days 0 and 4, mice were injected with either: (i) glucose $5 \%$; (ii) Gem at $7 \mathrm{mg} \cdot \mathrm{kg}^{-1}$; (iii) NO nanoparticles at a Gemequivalent dose of $7 \mathrm{mg} \cdot \mathrm{kg}^{-1}$ and (iv) $\mathbf{N 1 5}$ nanoparticles at a Gem-equivalent dose of $7 \mathrm{mg} \cdot \mathrm{kg}^{-1} . \mathrm{On}$ days 7, 11 and 14, mice were injected with either: (i) glucose $5 \%$; (ii) Gem at 4 mg.kg ${ }^{-1}$; (iii) No nanoparticles at a Gem-equivalent dose of $4 \mathrm{mg} \cdot \mathrm{kg}^{-1}$ and (iv) N15 nanoparticles at a Gemequivalent dose of $4 \mathrm{mg} \cdot \mathrm{kg}^{-1}$. The injected volume was $10 \mu \mathrm{L} \cdot \mathrm{g}^{-1}$ of body weight. The mice were regularly monitored for changes in tumor size and weight. ANOVA two-way with Tukey's correction test was used to determine statistical differences. The tumor growth inhibition (TGI) was calculated as follows: TGI $(\%)=\left(1-\mathrm{V}_{\mathrm{t}} / \mathrm{V}_{\mathrm{c}}\right) \times 100$, where $\mathrm{V}_{\mathrm{t}}$ and $\mathrm{V}_{\mathrm{c}}$ are the mean tumor volume of treated and control groups at the end of the study, respectively 


\subsection{In vivo and ex vivo fluorescence imaging}

Images were acquired using the IVIS Lumina LT Series III (PerkinElmer, USA). Excitation was set at $745 \mathrm{~nm}$ and emission was recovered on the $810-875 \mathrm{~nm}$ emission filter. For quantification, a region of interest (ROI) was automatically drawn around the mice liver (in vivo studies) or around the organs (ex vivo studies). Average radiant efficiency values (threshold of 5 and $30 \%$ for ex vivo and in vivo

images, respectively) were used for quantification.

In vivo imaging. A549 tumor-bearing nude mice injected with N0 and N15 nanoparticles were anesthetized with isoflurane $(3 \%)$ and placed in ventral position in the IVIS Lumina. In vivo fluorescence images were recorded before the beginning of the treatment, at $5 \mathrm{~h}$ and $24 \mathrm{~h}$ post each injection and at the end of the study (EoS, day 34). ANOVA two-way with Tukey's correction test was used to determine statistical differences.

Ex vivo imaging. Five A549 tumor-bearing nude mice were injected with No $(\mathrm{n}=2)$ and $\mathbf{N 1 5}(\mathrm{n}=3)$ and subjected to the treatment schedule presented in section 2.10 . The mice were euthanized $24 \mathrm{~h}$ after last injection to visualize ex vivo fluorescence in the different organs (tumor, liver, spleen, lung and kidney).

At day 34 (EoS), all remaining mice were euthanized and ex vivo fluorescence signal in the different organs (tumor, liver, spleen, lung and kidney) was recorded.

\section{Results and Discussion}

\subsection{Design rationale and selection of the building blocks}

Among the different ligands used for active targeting, ${ }^{8}$ biotin (also known as vitamin B7) has been widely used as a targeting moiety, ${ }^{40-43}$ due to overexpression of biotin receptors at the surface of many cancer cell types. ${ }^{44}$ Although more specific and potent ligands such as antibodies or peptides can be used, ${ }^{8,45}$ coupling of such large-size moieties to nanoparticles could be quite laborious, difficult to characterize and also harmful to the nanoparticle colloidal stability. In contrast, 
synthesis, purification and characterization of polymers functionalized by a small-size ligand such as biotin is generally much easier.

To confer imaging purposes, a near-infrared (NIR) dye, cyanine7.5 (Cy7.5), was selected. This dye can be effectively utilized for noninvasive in vivo imaging, due to the emission in the "biological transparency NIR window" in the 700-900 nm region, ${ }^{46}$ which helps overcoming issues such as tissue scattering and background absorption at lower wavelength.

Two heterotelechelic polymer prodrugs were synthesized by "drug-initiated" synthesis of gemcitabine-polyisoprene (Gem-PI) by SG1-mediated radical polymerization, followed by nitroxide exchange reaction to substitute the terminal SG1 nitroxide by a functional TEMPO nitroxide bearing either biotin or Cy7.5. Gem was chosen as a model anticancer drug because of its activity against numerous solid tumors ${ }^{47}$ whereas PI appeared as a suitable materials for biomedical applications according to its biocompatibility ${ }^{48}$ due to similarity with natural terpenoids and its previous safe use in vitro and in vivo. ${ }^{17,21,23,27}$ The presence of SG1 at the $\omega$ chain-end of NMPsynthesized polymers can be exploited by diverse techniques ${ }^{16}$ for post-functionalization purposes. We recently demonstrated that the nitroxide exchange reaction ${ }^{49}$ was a facile synthetic approach to synthesize heterotelechelic polymers bearing two different biological moieties. ${ }^{28}$ This reaction presented several benefits compared to alternative routes, such as the absence of catalyst, reactant or byproduct, a simplified work-up, almost quantitative yields and stoichiometric amounts of functional nitroxides. The driving forces are the formation of a more thermally stable PI-TEMPO macroalkoxyamine than PI-SG1.

\subsection{Heterotelechelic polymer prodrug synthesis}

AMA-SG1 was functionalized with Gem via PyBOP coupling ${ }^{17}$ and the resulting Gem-AMA-SG1 was used to initiate the polymerization of isoprene under SG1 control to yield Gem-PI-SG1 (GemPI and Gem-PI') with $M_{\mathrm{n}, \mathrm{SEC}}$ values of $2310 \mathrm{~g} \cdot \mathrm{mol}^{-1}(\mathrm{conv} .=27 \%)$ and $4750 \mathrm{~g} \cdot \mathrm{mol}^{-1}$ (conv. = 
$52 \%)$, relatively low dispersities $(Ð=1.22-1.30)$ and DL of 12 and $6 \mathrm{wt} \%$, respectively (Scheme $1 b$ and Table 1).

(a)<smiles>O=C(O)CCCC1C2CC3CC(C2)N1C(=O)N3</smiles><smiles>CCOCCOCCOCCOCCOCCOCCO</smiles><smiles>O=C1NC(CCCCC(=O)OCCO)C(CCCOCCOCCOCCOCCO)N1</smiles>

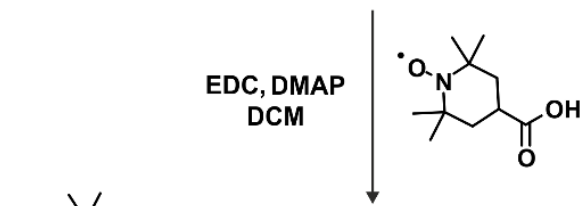<smiles>CCOCCOCCOCCOC(=O)CCCCC1SCC2NC(=O)NC21</smiles>

(b)
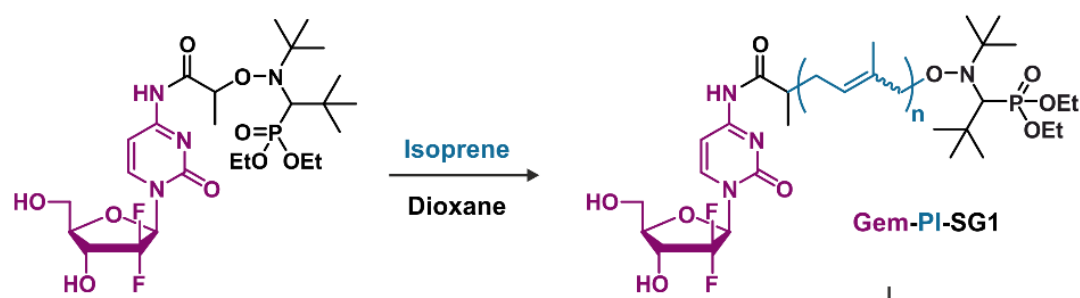

Gem-AMA-SG1

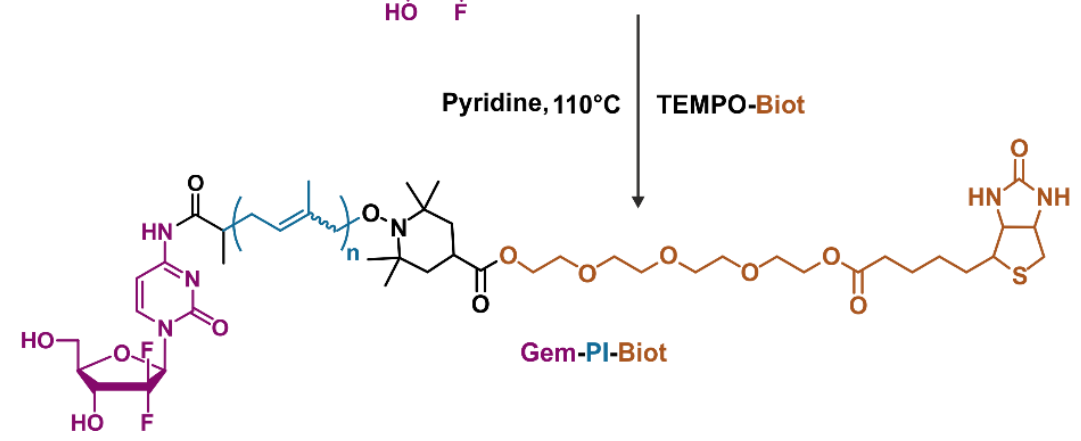

Scheme 1. (a) Synthesis of TEMPO-Biot and (b) heterobifunctional Gem-PI-Biot polymer prodrug by "drug-initiated" nitroxide-mediated polymerization (NMP) of isoprene from Gem-AMA-SG1 alkoxyamine followed by nitroxide exchange from TEMPO-Biot.

In parallel, TEMPO was functionalized with Biot to further perform the nitroxide exchange and obtain the desired heterotelechelic polymer Gem-PI-Biot. Note that to increase hydrophilicity to the vicinity of Biot and promote its positioning at the surface of the nanoparticles, a TEG spacer was inserted between Biot and TEMPO. More specifically, Biot was first reacted with TEG via EDC coupling with an overall yield of $87 \%$, followed by coupling of Biot-TEG with TEMPO with a 
$65 \%$ yield (Scheme 1a). Finally, the nitroxide exchange reaction was performed in pyridine at $110^{\circ} \mathrm{C}$ on Gem-PI-SG1 (Gem-PI) to give Gem-PI-Biot (Scheme $1 \mathrm{~b}$ and Table 1), which presented a $M_{\mathrm{n}}$ of $1960 \mathrm{~g} \cdot \mathrm{mol}^{-1}$ and a dispersity of 1.31. Importantly, SEC traces (DRI detector) of the starting Gem-PI and the obtained Gem-PI-Biot were almost perfectly overlaid, indicating the absence of irreversible chain termination reactions (Figure S1a). The functionalization yield was calculated by ${ }^{1} \mathrm{H}$ NMR by comparing the visible protons of Biot $(\delta=4.56-4.47,4.33,4.23,3.76-3.58,3.16$ and $2.93 \mathrm{ppm})$ and the aromatic and anomeric proton peaks of $\mathrm{Gem}(\delta=8.26,7.48$ and $6.26 \mathrm{ppm})$ giving a Biot/Gem molar ratio of 0.96, indicating quantitative functionalization (Figure S2). This result was further supported by disappearance of the characteristic peak associated to the proton in $\alpha$ position to the phosphorus atom of SG1 (3.2-3.4 ppm). 
(a)

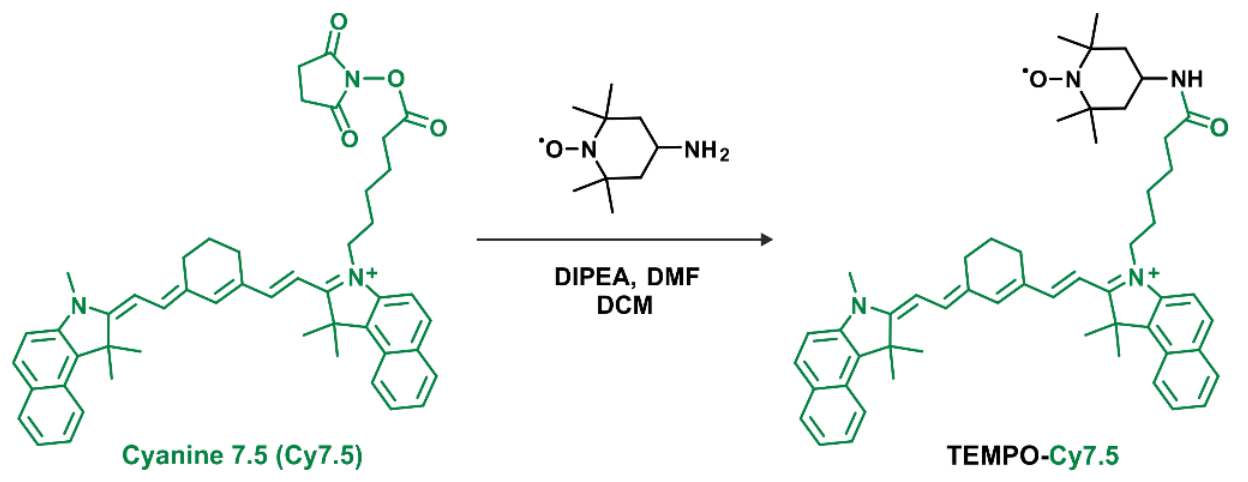

(b)

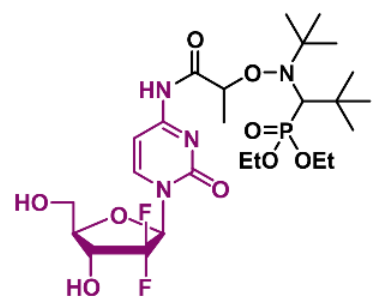

Gem-AMA-SG1
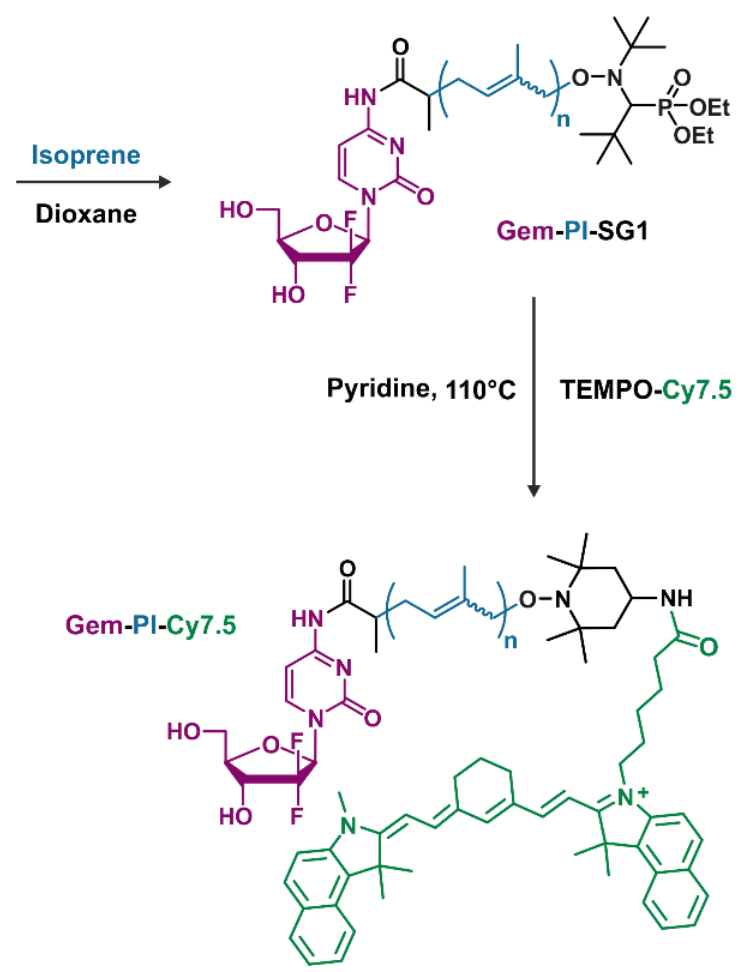

Scheme 2. (a) Synthesis of TEMPO-Cy7.5 and (b) heterobifunctional Gem-PI-Cy7.5 polymer prodrug by "drug-initiated" nitroxide-mediated polymerization (NMP) of isoprene from GemAMA-SG1 alkoxyamine followed by nitroxide exchange from TEMPO-Cy7.5.

Similarly, TEMPO was reacted with Cy7.5 NHS ester, to give TEMPO-Cy7.5 with an overall yield of $86 \%$ (Scheme 2a). After nitroxide exchange in pyridine at $110^{\circ} \mathrm{C}$ from Gem-PI', the fluorescent heterotelechelic polymer Gem-PI-Cy7.5 was obtained (Scheme 2b), with $M_{\mathrm{n}}$ of $5260 \mathrm{~g} \cdot \mathrm{mol}^{-1}$ and a dispersity of 1.37. SEC traces (DRI detector) showed a very slight migration towards higher molar masses, likely due to a change in the hydrodynamic volume of the polymer caused by the positive charge of Cy7.5 (Figure S1b). By ${ }^{1} \mathrm{H}$ NMR, it was possible to calculate the yield of 
functionalization by comparing aromatic proton peaks of Cy7.5 $(\delta=8.16-7.32 \mathrm{ppm})$ and the anomeric proton peak of Gem $(\delta=6.26 \mathrm{ppm})$. Note that because of signal overlap, it was necessary to subtract Gem aromatic proton signals from Cy7.5 aromatic proton signals. A Cy7.5/Gem molar ratio close to $1(0.92)$ was calculated, which suggested a nearly quantitative functionalization of the chain-end by TEMPO-Cy7.5 (Figure S3). This result was also supported by complete disappearance of the characteristic signal to the proton in $\alpha$ position to the phosphorus atom of SG1 (3.2-3.4 ppm). Bare PI used as control was also synthesized from AMA-SG1 and had a $M_{\mathrm{n}}$ of $2140 \mathrm{~g} \cdot \mathrm{mol}^{-1}$ and a dispersity of 1.18 (Table 1).

Table 1. Macromolecular and Structural Properties of PI-SG1, Gem-PI-SG1, Gem-PI-Biot and Gem-PI-Cy7.5 Polymer Prodrugs.

\begin{tabular}{|c|c|c|c|c|c|c|c|}
\hline Prodrug & $\begin{array}{c}M_{\mathrm{n}, \mathrm{SEC}}{ }^{a} \\
\left(\mathrm{~g} \cdot \mathrm{mol}^{-1}\right)\end{array}$ & $\boldsymbol{D}^{a}$ & $\begin{array}{c}M_{\mathrm{n}, \mathrm{NMR}} \\
\left(\mathrm{g} \cdot \mathrm{mol}^{-1}\right)\end{array}$ & $D P_{\mathbf{n}, \mathbf{N M R}}{ }^{e}$ & Biot/Gem ${ }^{f}$ & Cy7.5/Gem ${ }^{f}$ & $\begin{array}{c}\text { Drug loading } \\
(\mathbf{w t . \%})^{g}\end{array}$ \\
\hline $\mathbf{P I}^{h}$ & 2140 & 1.18 & - & - & - & - & - \\
\hline Gem-PI & 2310 & 1.22 & $3293^{b}$ & 57 & - & - & 11.6 \\
\hline Gem-PI-Biot & 1960 & 1.31 & $3780^{c}$ & 42 & 0.96 & - & 13.6 \\
\hline Gem-PI' & 4750 & 1.30 & $4580^{b}$ & 58 & - & - & 5.6 \\
\hline Gem-PI-Cy7.5 & 5260 & 1.37 & $5890^{d}$ & 70 & - & 0.92 & 5.1 \\
\hline \multicolumn{8}{|c|}{ 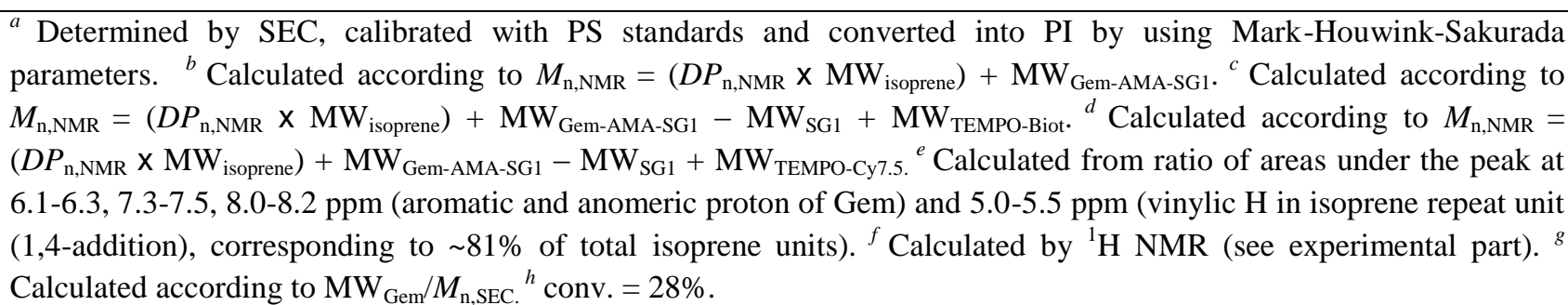 } \\
\hline
\end{tabular}

\subsection{Nanoparticle formulation and drug release}

NIR-emitting, targeted polymer prodrug nanoparticles were prepared at $2.5 \mathrm{mg} \cdot \mathrm{mL}^{-1}$ by concomitant nanoprecitation of blends composed of Gem-PI-Biot, Gem-PI-Cy7.5 and Gem-PI. By varying the initial weight fraction of Gem-PI-Biot $(0,15,50$ and 90 wt.\%) and fixing that of GemPI-Cy7.5 (10 wt.\%), nanoparticles with increasing amount of Biot were prepared and termed $\mathbf{N x}$ 
(with $\mathrm{x}$ being the weight fraction in Gem-PI-Biot, $\mathrm{x}=0,15,50$ and 90). Bare control nanoparticles were prepared from PI and monofunctional polymer prodrug nanoparticles from Gem-PI (Table 2). Bare PI nanoparticles had an average diameter of $140 \mathrm{~nm}$, whereas monofunctional Gem-PI nanoparticles were smaller $\left(D_{\mathrm{z}}=99 \mathrm{~nm}\right)$. Adding 10 wt.\% of Gem-PI-Cy7.5 during the nanoprecipitation almost doubled the size $\left(\mathbf{N 0}, D_{\mathrm{z}}=180 \mathrm{~nm}\right)$, whereas the addition of $15 \mathrm{wt} . \%$ of Gem-PI-Biot led to a substantial decrease of the diameter $\left(\mathbf{N 1 5}, D_{z}=118 \mathrm{~nm}\right)$. Such variations may be explained by the increase of the HLB when Gem-PI-Biot is used (Table S1) and by electrostatic repulsions with Cy7.5-functionalized polymers. Further increase of the initial weight fraction of Gem-PI-Biot up to 50 and $90 \mathrm{wt} \%$ did not significantly impact the diameter, as $D_{\mathrm{z}}=137 \mathrm{~nm}$ for $\mathbf{N 5 0}$ and $142 \mathrm{~nm}$ for N90. All nanoparticles presented low PSD values ranging from 0.14 to 0.18 and strongly negative zeta potentials, suggesting high colloidal stabilization, as already seen for PIbased prodrug nanoparticles. ${ }^{17,21,23}$ N0 and N90 nanoparticles, that exhibit extreme amounts of Gem-PI-Biot, were also characterized by cryo-TEM and displayed spherical morphologies and sizes in agreement with those determined by DLS (Figure 2a and $2 b$ ).

Table 2. Characterization of PI, Gem-PI, N0, N15, N50 and N90 Prodrug Nanoparticles.

\begin{tabular}{ccccc}
\hline Nanoparticle & $\begin{array}{c}\boldsymbol{D}_{z}^{a} \\
(\mathbf{n m})\end{array}$ & PSD $^{a}$ & $\begin{array}{c}\boldsymbol{\zeta}^{a} \\
(\mathbf{m V})\end{array}$ & Drug Loading (wt.\%) $^{\boldsymbol{b}}$ \\
\hline PI & 140 & 0.15 & -62 & - \\
Gem-PI $^{\boldsymbol{c}}$ & 99 & 0.17 & -29 & 11.6 \\
$\mathbf{N 0}^{\boldsymbol{c}}$ & 180 & 0.16 & -37 & 10.4 \\
$\mathbf{N 1 5}^{\boldsymbol{c}}$ & 118 & 0.17 & -43 & 10.6 \\
$\mathbf{N 5 0}^{c}$ & 137 & 0.18 & -41 & 11.1 \\
$\mathbf{N 9 0}^{c}$ & 142 & 0.14 & -34 & 11.8 \\
\hline
\end{tabular}

${ }^{a}$ Measured by dynamic light scattering (DLS). ${ }^{b}$ Calculated according to $\mathrm{MW}_{\mathrm{Gem}} / M_{\mathrm{n}, \mathrm{SEC}}{ }^{c}$ Containing $10 \mathrm{wt} . \%$ Gem-PI-Cy7.5. 
Because each heterobifunctional polymer prodrug is functionalized by a Gem molecule, the overall amount of Gem, and therefore DL values, stayed constant whatever the composition of nanoparticles obtained by nanoprecipitation of Gem-PI/Gem-PI-Biot/Gem-PI-Cy7.5 blends. It is an important feature and a clear advantage of using heterotelechelic polymer prodrugs compared to monofunctional materials as DL would have varied if the corresponding monofunctional polymers would have been used.

All nanoparticles were stable with no formation of visible precipitate over time. For instance, the long-term colloidal stability of nanoparticles N0, N15 and PI was monitored in water and exhibited rather constant average diameters and particle size distributions for at least 55 days (Figure 2c). Note that the smaller average diameter of N15 compared to that of N0 is likely due to the presence of hydrophilic TEG-Biotin moieties at the surface of the nanoparticles (supported by a higher predicted HLB, Table S1), leading to enhanced colloidal stability. Their long-term colloidal stability was also assessed in cell culture medium where average diameters were constant at least up to 14 days (Figure S4a), whereas their incubation in PBS ( $\mathrm{pH}$ 7.2-7.4) led to rapid colloidal instability (Figure S4b). 

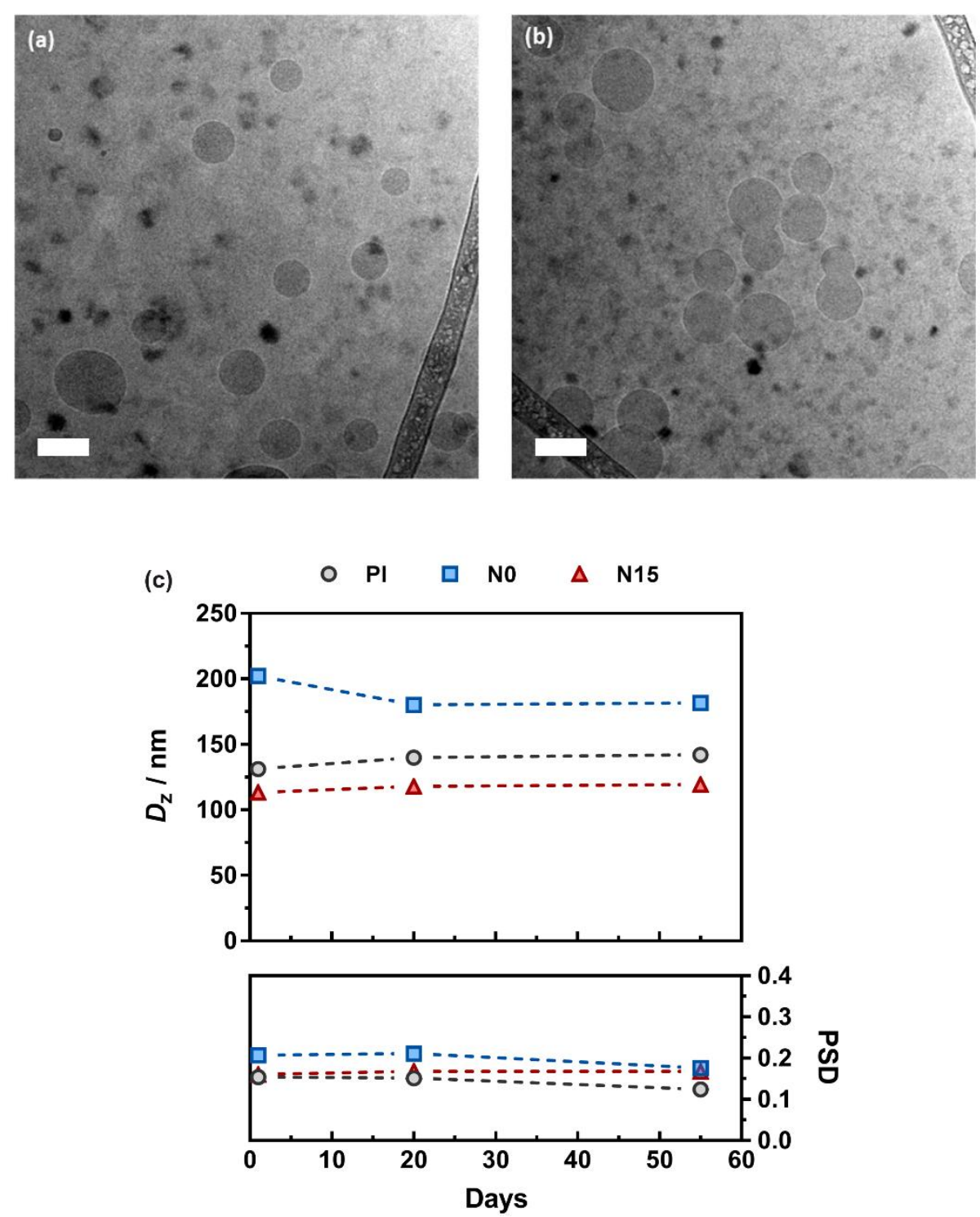

Figure 2. Representative TEM images of (a) N0 nanoparticles (scale bar = $100 \mathrm{~nm}$ ) and (b) N90 nanoparticles (scale bar $=100 \mathrm{~nm}$ ). (c) Evolution of the intensity-averaged diameters $\left(D_{\mathrm{z}}\right)$ and the particle size distributions (PSD) measured by DLS in water of nanoparticles PI, N0 and N15.

To study the cellular internalization, a UV-Vis dye like rhodamine B was preferred to Cy7.5 to allow compatibility with the filters of the FACS apparatus. Gem-PI-Rho $\left(M_{n}\right.$ SEC $\left.=3842, Ð=1.30\right)$ was therefore prepared following a similar synthetic route ${ }^{27}$ and blended (10 wt.\%) with Gem-PI and Gem-PI-Biot prior co-nanoprecipitation to achieve Rho-labeled nanoparticles with variable amounts of Biot: N0*, N15*, N50* and N90* (containing 0, 15, 50 and 90 wt.\% of Gem-PI-Biot, 
respectively). Their average size ranged between 169 and $247 \mathrm{~nm}$ and presented low PSD in the 0.15-0.23 range (Table S2).

To investigate Gem release over time, $\mathbf{N 9 0}$ and $\mathbf{G e m}-\mathbf{P I}$ were incubated at $37^{\circ} \mathrm{C}$ in human serum to mimic the biological environment. Monofunctional Gem-PI and heterofunctional N90 nanoparticles released 6.1 and less than 0.5 mol.\% of Gem after $24 \mathrm{~h}$, respectively (Figure S5). Although incubation of the nanoparticles in the presence of Cathepsin $\mathrm{B}$, one of the relevant enzymes for this type of prodrug, ${ }^{50}$ increased the amount of released Gem by almost a of factor 2 , it stayed rather modest (Figure S5). This result is in agreement with previous Gem release studies from heterobifunctional polymer prodrug nanoparticles for combination therapy. ${ }^{28}$ It was indeed suggested that such a dual functionalization (compared to a simple one) affected the supramolecular organization of the polymer chains during the nanoparticle self-assembly, by altering the placement of Gem within the nanoparticles (i.e., on the surface $v s$ in the core) and therefore its release kinetics. In fact, given the short polymer chains, it indeed seemed rather unlikely to have both chain-ends displayed at the nanoparticle surface. In our case, hydrophilicity of Biot-TEG moiety may promote its surface positioning whereas most of the Gem chain-ends would be buried inside the nanoparticle core. This hypothesis is supported by the higher HLB value predicted for model Gem-PI-Biot compared to model Gem-PI (Table S1). Furthermore, having biotin at the nanoparticle surface is mandatory for targeting purposes to achieve its recognition by overexpressed biotin receptors. It is also worth noting that Gem release kinetics from Gem-PI and N90 both rapidly reached a plateau. It suggested that only Gem present on the nanoparticle surface was cleaved by specific enzymes, whereas the high colloidal stability of the nanoparticles prevented further Gem release until nanoparticles got disassembled, for instance in vivo as suggested by the significant anticancer efficacy of monofunctional polymer prodrug nanoparticles. ${ }^{17,20}$ 


\subsection{Cellular internalization and in vitro cytotoxicity}

Human lung cancer cell line A549 was chosen because of its susceptibility to Gem ${ }^{17,19}$ and because of overexpression of biotin receptor ${ }^{40}$ that may allow for biotin targeting to be evaluated. ${ }^{42,43,51-55}$ Rho-labeled nanoparticles with increasing weight fractions of biotin N0*, N15*, N50* and N90* were incubated with A549 cells at different times and temperatures, then Rho fluorescence signal was measured by flow cytometry (Figure 3).

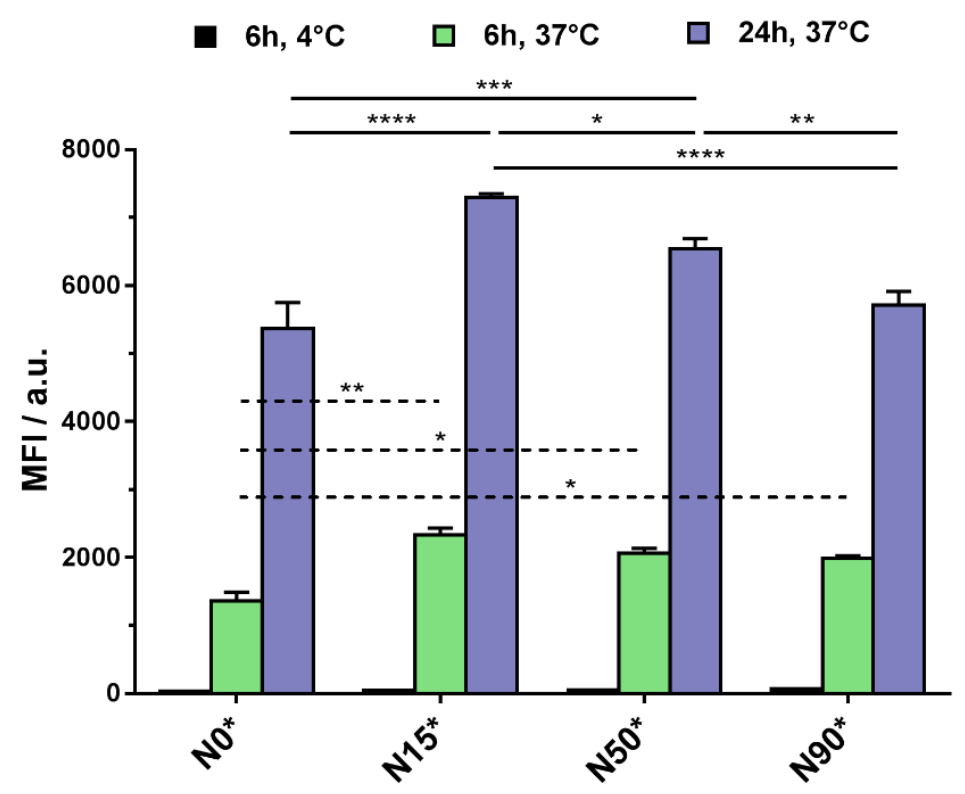

Figure 3. Cellular internalization of biotinylated N15*, N50* and N90* nanoparticles and nonbiotinylated N0* nanoparticles in A549 cancer cells for $6 \mathrm{~h}$ at $4^{\circ} \mathrm{C}$ and for 6 and $24 \mathrm{~h}$ at $37^{\circ} \mathrm{C}$. The values are the mean \pm SEM. $* p<0.05 ; * * p<0.01 ; * * * p<0.001 ; * * * * p<0.0001$.

The results indicated a significantly higher fluorescence intensity from targeted nanoparticles N15*, N50* and N90* compared to non-targeted N0* for both time points at $37^{\circ} \mathrm{C}$. Even though there was no significative difference between all biotinylated nanoparticles $\mathbf{N 1 5}^{*}, \mathbf{N 5 0}$ * and $\mathbf{N 9 0} *$ at $6 \mathrm{~h}$, a clear trend after $24 \mathrm{~h}$ was noticed in which the lower the amount of biotin, the higher the internalization, resulting in $\mathbf{N 1 5}^{*}$ having the best cell uptake. This result is in line with a previous study on PLA- $b$-PEG-Biotin nanoparticles whose surface amount of biotin was varied from 0 to 76 
mol. $\%$ and showed the best binding to streptavidin for 19 mol. $\%$ biotin. ${ }^{43}$ Detrimental affinity for higher amounts of biotin was assigned to hydrophobic interactions between Biot moieties because of increased local concentration and/or receptor overbinding. Also, since biotin groups are here likely located rather close to the nanoparticle surface, steric hindrance precluding efficient ligand/receptor interaction even for high Biot surface amounts cannot be ruled out. When nanoparticles were incubated with cells at $4{ }^{\circ} \mathrm{C}$ for $6 \mathrm{~h}$, a strong reduction of the fluorescence was observed and the signal was negligible, thus suggesting an internalization via an active mechanism, likely by endocytosis similarly to comparable biotinylated, polyisoprenoid prodrug nanoparticles. ${ }^{42}$

The in vitro cytotoxicity at $72 \mathrm{~h}$ of free Gem, PI, non-targeted Gem-PI and N0 nanoparticles, together with targeted N15, N50 and N90 nanoparticles was evaluated on human lung cancer cell line A549 by means of an ATP quantification assay (Figure 4). Note that the different nanoparticles contained $10 \mathrm{wt}$ \% of Gem-PI-Cy7.5 to mimic the same formulations that will be further used in vivo in the next sections.

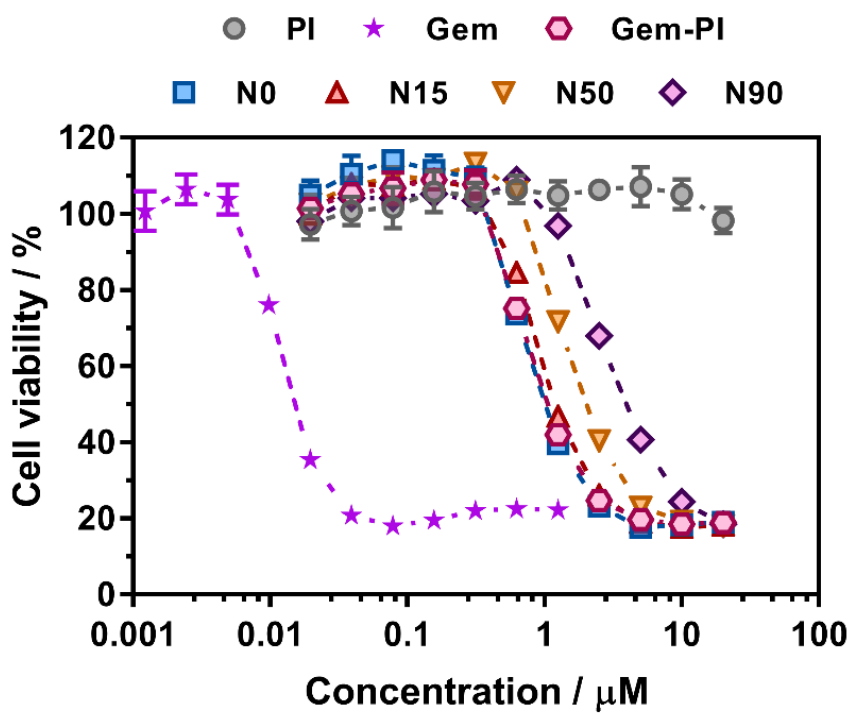

Figure 4. Cell viability of A549 cells after incubation for $72 \mathrm{~h}$ with increasing concentrations of free Gem, bare PI, non-targeted Gem-PI and N0, and targeted N15, N50 and N90 nanoparticles. The values are the mean \pm SD. 
First, bare PI nanoparticles did not show any toxicity at all tested concentrations, confirming their safety and excluding potential toxicity from the carrier. Free Gem showed a very low $\mathrm{IC}_{50}$ of $15 \mathrm{nM}$, whereas all prodrug nanoparticles had higher $\mathrm{IC}_{50}$ values. This is expected due to their prodrug nature, thus requiring their cleavage and drug release from the polymer to exert their activity. To be noted that Gem is known to be quickly metabolized in vivo, ${ }^{56}$ which fully justified the use of Gembased prodrugs to protect the parent drug from early degradation when administered in vivo. As for polymer prodrug nanoparticles, Gem-PI and No nanoparticles presented almost the same $\mathrm{IC}_{50}(1.06$ and $1.02 \mu \mathrm{M}$, respectively), thus excluding potential toxicity from the dye. Biotinylated nanoparticles $\mathbf{N 1 5}$ had a very similar $\mathrm{IC}_{50}$ of $1.19 \mu \mathrm{M}$, whereas increasing the amount of biotin led to a decrease in cytotoxicity, as $\mathbf{N 5 0}$ and $\mathbf{N 9 0}$ had an $\mathrm{IC}_{50}$ of 2.02 and $3.92 \mu \mathrm{M}$, respectively. This trend is in good agreement with two previous observations we made: (i) a much slower Gem release when heterobifunctional Gem-PI-Biot are used in place of monofunctional Gem-PI (Figure S5) and (ii) a lower cell internalization of nanoparticles when the surface amount of Biot is too high (Figure 3). Increasing the Gem-PI content at the expense of Gem-PI-Biot likely resulted in higher Gem release kinetics, that seemed to be the predominant effect compared to a better cell uptake for biotinylated nanoparticles.

Given internalization and cell viability data, N15 nanoparticles seemed to be the best compromise in terms of cell uptake and cytotoxicity. Accordingly, they were chosen to be compared to N0 nanoparticles for further in vivo experiments.

\subsection{In vivo anticancer activity}

The in vivo anticancer efficacy of targeted N15 and non-targeted N0 nanoparticles was assessed against human lung tumor A549 xenograft model in mice after intravenous injections on days 0, 4, 7, 11 and 15, at a Gem-equivalent dose of $7 \mathrm{mg} \cdot \mathrm{kg}^{-1}$ up to day 4, and at a Gem-equivalent dose of 4 mg. $\mathrm{kg}^{-1}$ for the rest of the treatment (see experimental part and Figure 5a). Evolution of the tumor volume and body weight of the mice were monitored over a period of 22 days and compared to that 
of Gem administrated at the same dose and control mice (glucose 5\%), while innocuousness of control PI nanoparticles has already been demonstrated. ${ }^{17}$

(a)

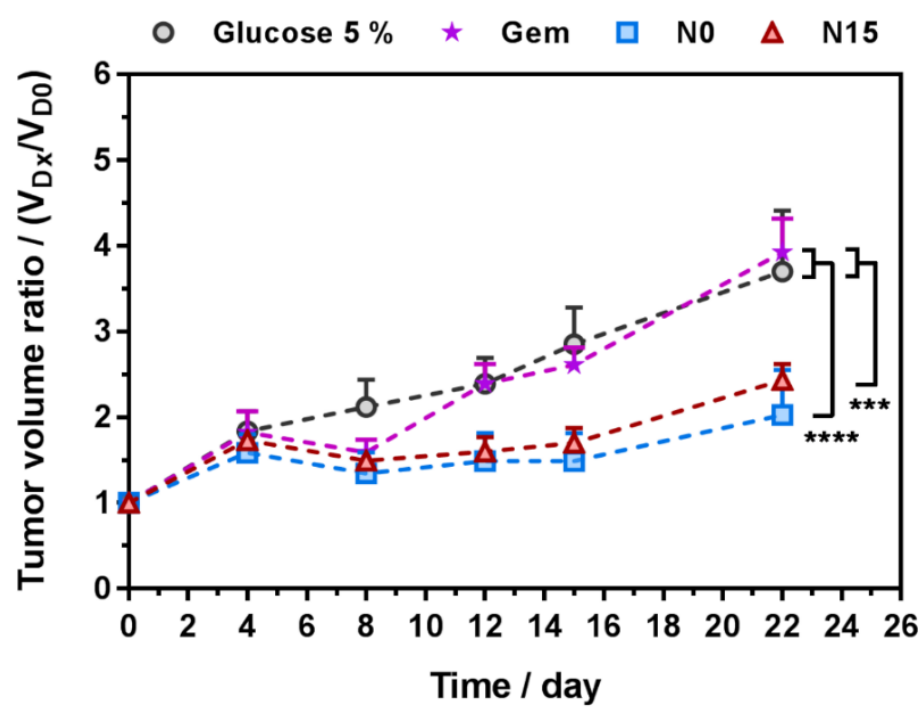

(b)

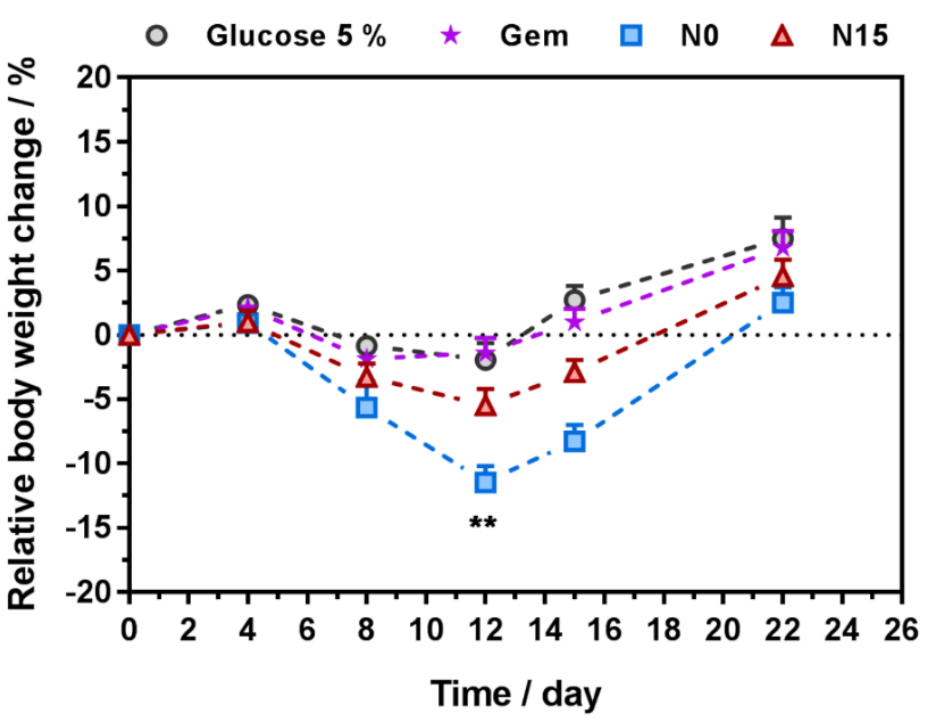

Figure 5. In vivo anticancer efficacy of Gem, control (glucose 5\%), N0 and N15 nanoparticles after intravenous administration on days $0,4,7,11$ and 15 , at a Gem-equivalent dose of $7 \mathrm{mg} \cdot \mathrm{kg}^{-1}$ up to day 4 , and at a Gem-equivalent dose of $4 \mathrm{mg} \cdot \mathrm{kg}^{-1}$ for the rest of the treatment to A549 tumor bearing mice: (a) tumor volume ratio as a function of time; (b) relative body weight change as a function of time. The values are the mean \pm SEM $(\mathrm{n}=8)$. Statistical differences: (a) $* * * p \leq 0.001$, N15 vs Gem or control; **** $p<0.0001$, N0 vs Gem or control; (b) ** $p<0.01$, N0 vs N15.

After 22 days, untreated- and Gem-treated mice reached a similar tumor volume ratio of 3.7 and 3.9, respectively, showing the inefficacy of free Gem under this treatment schedule. In contrast, 
mice treated with polymer prodrug nanoparticles $\mathbf{N O}$ at the same equivalent dose of Gem, led to a significant reduction of the tumor growth compared to control experiments, with tumor volume ratios reaching a value of 2.4. Such improvement corresponded to a tumor growth inhibition $\sim 40 \%$ compared to vehicle (control) and Gem-treated mice, which confirmed the beneficial effect of GemPI prodrug nanoparticles over administration of free Gem. Biotinylated nanoparticles N15 showed a very similar anticancer efficacy than No, in excellent agreement with in vitro cell viability experiments. It showed that the greater cell uptake observed in vitro did not, also in vivo, prevail over the much slower Gem release kinetics resulting from the heterobifunctionalization, and that the anticancer activity of heterobifunctional polymer prodrug nanoparticles was maintained. Despite the much slower Gem release kinetic, heterobifunctional nanoparticles N15 maintained the same anticancer activity than monofunctional prodrug N0, potentially because of the higher uptake but also because of competition with free biotin that may attenuate the difference between both types of nanoparticles.

Interestingly enough, biotinylated nanoparticles N15 were advantageous in terms of body weight loss compared to N0. Indeed, more than $11 \%$ weight loss was witness at day 12 with N0 (leading to 2 dead mice after the second injection at day 4 , likely because of the CARPA effect), ${ }^{57,58}$ whereas N15 and control groups ranged from -2 to $-5 \%$ weight, with no loss of mice (Figure $5 \mathrm{~b}$ ). This would allow for an increase of the dose of N15 and potentially a greater therapeutic index compared to non-biotinylated nanoparticles N0. This reduction of toxicity was already noticed for other biotinylated nanoparticles. ${ }^{59}$

\subsection{In vivo and ex vivo fluorescence imaging}

Given nanoparticles N0 and N15 were already tagged with the NIR fluorescent dye Cy7.5, it allowed for their in vivo fate and accumulation to be investigated. The advantage of Cy7.5 over other imaging options lies on its emission in the far NIR region, which favors higher penetration 
depth and reduces the possibility of artifacts from biological tissue. ${ }^{46}$ Moreover, this dye is a wellestablished imaging agent to visualize tumor on mice model. ${ }^{60-62}$ Mice were imaged before starting the treatment at day 0 (PreT), $5 \mathrm{~h}$ and $24 \mathrm{~h}$ after injection at day $0(1 \mathrm{~T}), 4(2 \mathrm{~T}), 7(3 \mathrm{~T}), 11(4 \mathrm{~T})$ and 14 (5T) and at the end of the study (EoS). Representative images from N0- and N15-treated mice over time are gathered in Figure 6a.
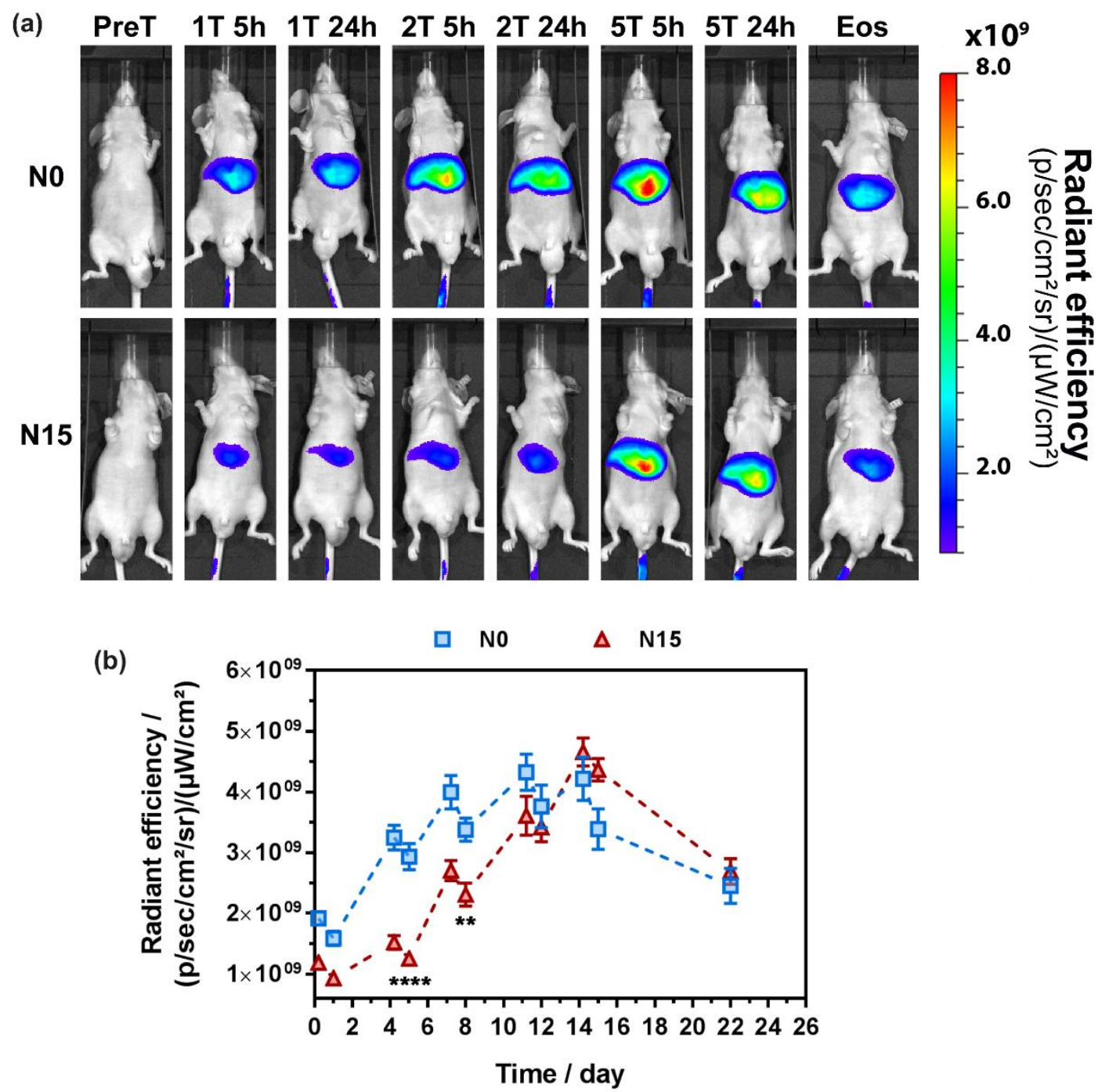

Figure 6. (a) In vivo representative images of tumor-bearing mice after intravenous injection of N0 or N15 nanoparticles. Excitation at $745 \mathrm{~nm}$ and emission collection at 810-875 $\mathrm{nm}(\mathrm{T}=$ treatment, Eos = end of study). (b) Fluorescence signal (Average radiant efficiency; 30\% threshold) of the mice liver injected with N0 and $\mathbf{N 1 5}$ nanoparticles in function of time. The values represent mean \pm $\operatorname{SEM}(\mathrm{n}=8) . * * p<0.01, * * * * p<0.0001$. 
As expected, a strong fluorescent signal was detected in the liver all along the monitoring. It is indeed well known that non-PEGylated nanoparticles are rapidly captured by the RES system and tend to accumulate in the liver. ${ }^{63}$ For both nanoparticles, a strong fluorescence signal was detected 5 $\mathrm{h}$ after each injection, then slightly decreased at $24 \mathrm{~h}$, before increasing again because of the next injection. However, a significant difference in terms of liver accumulation was noticed between the two nanoparticles up to day 8 (Figure 6). Indeed, accumulation of biotinylated nanoparticles N15 was found to be $57 \%$ less important than that of NO $24 \mathrm{~h}$ after $2 \mathrm{~T}$ and $32 \%$ less important $24 \mathrm{~h}$ after 3T (Figure 6b). At the fourth injection (4T), the amount of both nanoparticles was similar and they both underwent elimination once injections were stopped at day 14. This delayed liver accumulation for N15 might be explained by a different surface chemistry resulting from preferential positioning of TEG-Biot moieties at the nanoparticle surface, compared to N0. Because of the hydrophilicity of TEG-Biot and the very short EG chain, one can indeed imagine that such a compound could induce a slight stealth effect, like traditional PEG, and thus transiently allowing to escape opsonization and macrophage uptake.

Unfortunately, no clear signal from N0 or N15 could be detected in the region of the tumor, neither in ventral nor dorsal position. The circulation time of both nanoparticles was likely too low to induce a marked accumulation in tumor cells by the so-called EPR effect and/or biotin-mediated targeting.

All mice were then euthanized at day 34 , to study biodistribution and accumulation in the major organs. Other mice were also identically treated with nanoparticles N0 or N15 and sacrificed $24 \mathrm{~h}$ after the fifth injection to assess biodistribution right at the end of the treatment (Figure 7a and 7b). 


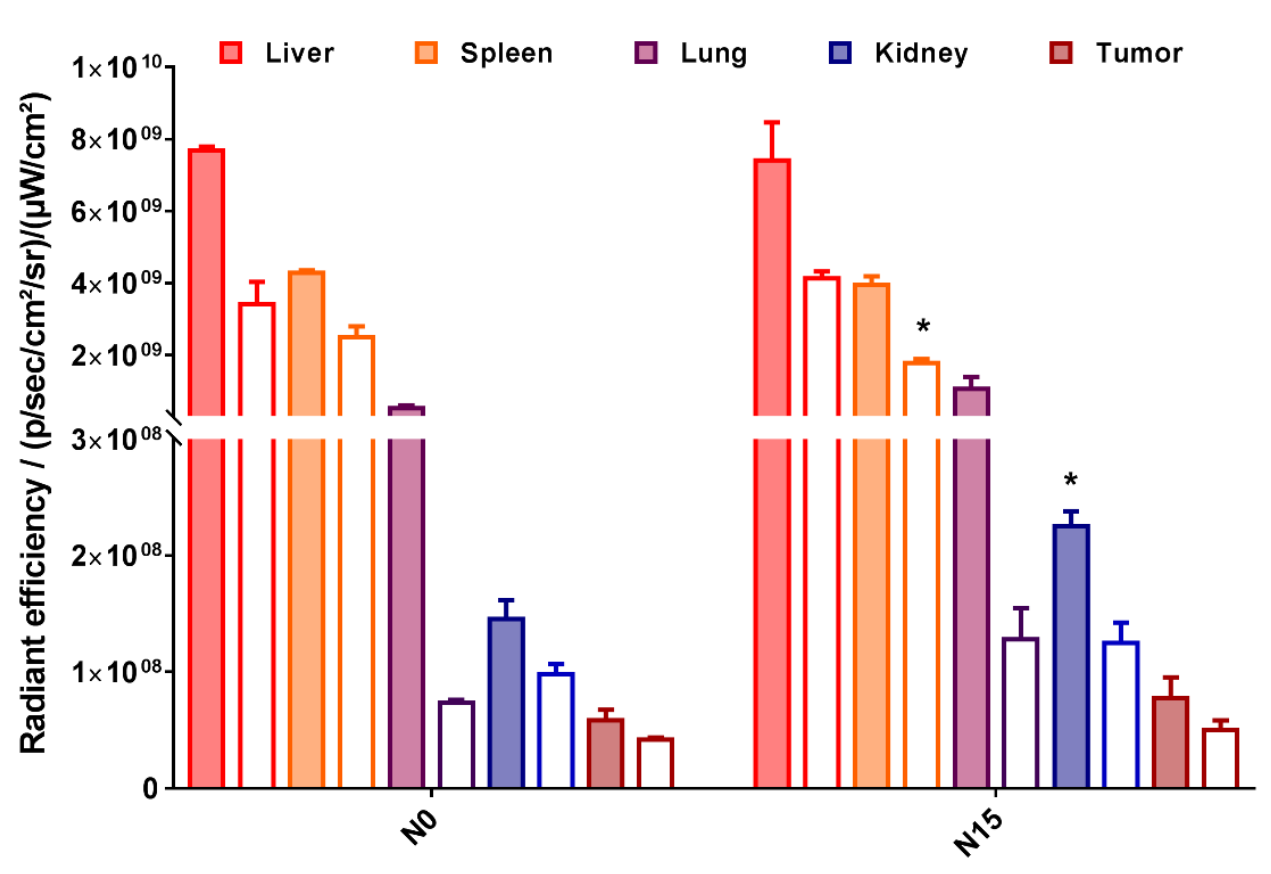

Figure 7. Ex vivo biodistribution of nanoparticles N0 and N15 in the liver (red), spleen (orange), lung (purple), kidney (blue) and tumor (brown) $24 \mathrm{~h}$ after the last injection (5T, filled bars) or at the end of the study (EoS, empty bars). ${ }^{*} p<0.05$ vs. No.

In agreement with in vivo imaging, both types of nanoparticles mostly accumulated in the organs of the RES system (liver and spleen) in a similar fashion, $24 \mathrm{~h}$ after the last injection. A significant accumulation was also found in the lung at $24 \mathrm{~h}$ post-5T (followed by rapid elimination until EoS), whereas a lower amount was found in the kidney, which is explained by the slow renal excretion of the nanoparticles (e.g., disassembled/degraded) due to their high colloidal stability.

As shown by fluorescence signal detected at both time points, nanoparticles N0 and N15 did accumulate into the tumors, which is in agreement with anticancer efficacy experiments. Interestingly, fluorescence signal found in tumors of N15-treated mice increased compared to that of N0-treated mice $\left(5.8 \times 10^{7}\right.$ in radiant efficiency for N0 vs. $7.7 \times 10^{7}$ for $\mathbf{N 1 5}$, that corresponds to a $35 \%$ increase), thus indicating a slightly better accumulation likely because of biotin surfacefunctionalization. Ex vivo biodistribution was also assessed at EoS. Overall, all organs showed a decrease in the average radiant efficacy over time due to nanoparticle clearance. Note that 
elimination from the lung was faster ( $\sim 87 \%$ for N0 and N15, respectively) compared to the other organs ( $\sim 55 \%$ for the liver, $\sim 50 \%$ for the spleen, $\sim 38 \%$ for the kidney).

\section{Conclusion}

To confer imaging and targeting abilities the simplest possible way to nanoparticles prepared by the "drug-initiated" method, two heterotelechelic polymers bearing Gem and either biotin for active targeting, or cyanine7.5 for in vivo imaging, were successfully synthesized by nitroxide-mediated polymerization of isoprene from a Gem-bearing alkoxyamine, followed by the nitroxide exchange reaction from a functional TEMPO nitroxide. These materials were well-controlled with nearly quantitative functionalization yields. They were then used to successfully prepare fluorescentlylabeled polymer prodrug nanoparticles with variable surface amounts of biotin. Nanoparticles containing the lowest amount of biotinylated polymer (15 wt. \%) demonstrated superior cancer cell uptake, as observed by FACS, and the highest cytotoxicity in vitro against lung cancer cells A549.

Biotinylated nanoparticles showed significantly higher efficacy than free Gem in vivo on human lung tumor A549 xenograft model in mice and displayed analogous anticancer activity than non-targeted counterparts, with an average tumor growth inhibition of $\sim 40 \%$. Moreover, nontargeted nanoparticles led to more than a $10 \%$ body weight loss conversely to biotinylated counterparts that induced much less toxicity to the mice, thus suggesting a better therapeutic index.

Incorporation of NIR-emitting dye in the polymer prodrugs structure successfully enabled the in vivo fate of drug-initiated synthesized PI nanoparticles to be monitored. We showed that biotinylated nanoparticles led to a delayed liver accumulation compared to non-biotinylated nanoparticles, indicating moderate stealth property likely due to hydrophilic TEG-Biot and the short EG chain. Also, ex vivo fluorescence imaging showed significant liver accumulation of both nanoparticles in agreement with in vivo imaging. It also suggested their accumulation into the tumors with a slightly higher amount of biotinylated nanoparticles than non-biotinylated 
counterparts. Nonetheless, it did not result in an improved anticancer activity, which was assigned to a much slower Gem release in presence of Biot at the other polymer extremity.

Whereas simplicity is a key aspect of polymer prodrug nanoparticles obtained from the "drug-initiated" method, their efficient targeting via simple surface functionalization of Gem-PI nanoparticles with biotin as a ligand was not sufficient to induce a significantly higher anticancer efficacy. This could be solved by either: (i) improving stealth properties and enhancing accessibility to biotin by using longer PEG chain than TEG and/or (ii) by using more selective targeting ligand with a greater affinity towards their targets such as peptide sequences or antibody fragments.

In conclusion, this work showed for the first time the applicability of this simple construction method to in vivo imaging and cancer cell targeting, and might stimulate the design of new functional materials for biomedical applications.

\section{Supplementary Information}

The Supporting Information is available free of charge on the ACS Publications website at DOI: < to be completed $>$. ${ }^{1} \mathrm{H}$ NMR spectra and SEC chromatograms of the polymer prodrugs, predicted HLB values of model prodrugs, DLS data of the nanoparticles and Gem release profiles.

\section{Acknowledgement}

This work was supported by the European Union's Horizon 2020 research and innovation programme under Marie Skłodowska Curie grant agreement no. 642028 (NABBA). The authors thank the Service de Microscopie Electronique (UFR de Biologie Intégrative, Université Paris-Sud) for Cryo-TEM analyses and Stéphanie Nicolaÿ for mass spectrometry analyses (Service d'Analyses des Médicaments et Métabolites (Institut Paris-Sud d'Innovation Therapeutique (IPSIT), Université Paris-Sud). Arkema is warmly acknowledged for kindly providing the SG1 nitroxide. CNRS and Université Paris-Sud are also acknowledged for financial support. 


\section{Reference}

1. Couvreur, P.; Vauthier, C. Nanotechnology: intelligent design to treat complex disease. Pharm. Res. 2006, 23, 1417-1450.

2. Tibbitt, M. W.; Dahlman, J. E.; Langer, R. Emerging frontiers in drug delivery. J. Am. Chem. Soc. 2016, 138, 704-717.

3. Torchilin, V. P. Micellar nanocarriers: pharmaceutical perspectives. Pharm. Res. 2007, 24, 1.

4. Samad, A.; Sultana, Y.; Aqil, M. Liposomal drug delivery systems: an update review. Curr. Drug Delivery 2007, 4, 297-305.

5. Elsabahy, M.; Wooley, K. L. Design of polymeric nanoparticles for biomedical delivery applications. Chem. Soc. Rev. 2012, 41, 2545-2561.

6. Wang, R.; Billone, P. S.; Mullett, W. M. Nanomedicine in action: an overview of cancer nanomedicine on the market and in clinical trials. J. Nanomater. 2013, $2013,1$.

7. Bobo, D.; Robinson, K. J.; Islam, J.; Thurecht, K. J.; Corrie, S. R. Nanoparticle-based medicines: a review of FDA-approved materials and clinical trials to date. Pharm. Res. 2016, 33, 2373-2387.

8. Nicolas, J.; Mura, S.; Brambilla, D.; Mackiewicz, N.; Couvreur, P. Design, functionalization strategies and biomedical applications of targeted biodegradable/biocompatible polymerbased nanocarriers for drug delivery. Chem. Soc. Rev. 2013, 42, 1147-1235.

9. Delplace, V.; Couvreur, P.; Nicolas, J. Recent trends in the design of anticancer polymer prodrug nanocarriers. Polym. Chem. 2014, 5, 1529-1544.

10. Chen, K.; Cai, H.; Zhang, H.; Zhu, H.; Gu, Z.; Gong, Q.; Luo, K. Stimuli-responsive polymer-doxorubicin conjugate: Antitumor mechanism and potential as nano-prodrug. Acta Biomater. 2019, 84, 339-355.

11. Dheer, D.; Nicolas, J.; Shankar, R. Cathepsin-sensitive nanoscale drug delivery systems for cancer therapy and other diseases. Adv. Drug Delivery Rev. 2019.

12. Duan, Z.; Zhang, Y.; Zhu, H.; Sun, L.; Cai, H.; Li, B.; Gong, Q.; Gu, Z.; Luo, K. StimuliSensitive Biodegradable and Amphiphilic Block Copolymer-Gemcitabine Conjugates SelfAssemble into a Nanoscale Vehicle for Cancer Therapy. ACS Appl. Mater. Interfaces 2017, 9, 3474-3486.

13. Kopeček, J.; Kopečková, P. HPMA copolymers: Origins, early developments, present, and future. Adv. Drug Delivery Rev. 2010, 62, 122-149.

14. Nicolas, J. Drug-initiated synthesis of polymer prodrugs: combining simplicity and efficacy in drug delivery. Chem. Mater. 2016, 28, 1591-1606.

15. Moad, G.; Rizzardo, E.; Thang, S. H. Living radical polymerization by the RAFT process-a second update. Aust. J. Chem. 2009, 62, 1402-1472. 
16. Nicolas, J.; Guillaneuf, Y.; Lefay, C.; Bertin, D.; Gigmes, D.; Charleux, B. Nitroxidemediated polymerization. Prog. Polym. Sci. 2013, 38, 63-235.

17. Harrisson, S.; Nicolas, J.; Maksimenko, A.; Bui, D. T.; Mougin, J.; Couvreur, P. Nanoparticles with in vivo anticancer activity from polymer prodrug amphiphiles prepared by living radical polymerization. Angew. Chem., Int. Ed. 2013, 52, 1678-1682.

18. Trung Bui, D.; Maksimenko, A.; Desmaële, D.; Harrisson, S.; Vauthier, C.; Couvreur, P.; Nicolas, J. Polymer prodrug nanoparticles based on naturally occurring isoprenoid for anticancer therapy. Biomacromolecules 2013, 14, 2837-2847.

19. Guégain, E.; Tran, J.; Deguettes, Q.; Nicolas, J. Degradable polymer prodrugs with adjustable activity from drug-initiated radical ring-opening copolymerization. Chem. Sci. 2018, 9, 82918306.

20. Maksimenko, A.; Bui, D. T.; Desmaële, D.; Couvreur, P.; Nicolas, J. Significant tumor growth inhibition from naturally occurring lipid-containing polymer prodrug nanoparticles obtained by the drug-initiated method. Chem. Mater. 2014, 26, 3606-3609.

21. Bao, Y.; Boissenot, T.; Guégain, E.; Desmaële, D.; Mura, S.; Couvreur, P.; Nicolas, J. Simple Synthesis of Cladribine-Based Anticancer Polymer Prodrug Nanoparticles with Tunable Drug Delivery Properties. Chem. Mater. 2016, 28, 6266-6275.

22. Bao, Y.; Nicolas, J. Structure-cytotoxicity relationship of drug-initiated polymer prodrug nanoparticles. Polym. Chem. 2017, 8, 5174-5184.

23. Bao, Y.; Guégain, E.; Mougin, J.; Nicolas, J. Self-stabilized, hydrophobic or PEGylated paclitaxel polymer prodrug nanoparticles for cancer therapy. Polym. Chem. 2018, 9, 687-698.

24. Louage, B.; Nuhn, L.; Risseeuw, M. D.; Vanparijs, N.; De Coen, R.; Karalic, I.; Van Calenbergh, S.; De Geest, B. G. Well-Defined Polymer-Paclitaxel Prodrugs by a Grafting-from-Drug Approach. Angew. Chem., Int. Ed. 2016, 55, 11791-11796.

25. Louage, B.; Van Steenbergen, M. J.; Nuhn, L.; Risseeuw, M. D.; Karalic, I.; Winne, J.; Van Calenbergh, S.; Hennink, W. E.; De Geest, B. G. Micellar Paclitaxel-Initiated RAFT Polymer Conjugates with Acid-Sensitive Behavior. ACS Macro Letters 2017, 6, 272-276.

26. Vinciguerra, D.; Tran, J.; Nicolas, J. Telechelic polymers from reversible-deactivation radical polymerization for biomedical applications. Chem. Commun. 2018, 54, 228-240.

27. Vinciguerra, D.; Denis, S.; Mougin, J.; Jacobs, M.; Guillaneuf, Y.; Mura, S.; Couvreur, P.; Nicolas, J. A facile route to heterotelechelic polymer prodrug nanoparticles for imaging, drug delivery and combination therapy. J. Control. Rel. 2018, 286, 425-438.

28. Vinciguerra, D.; Jacobs, M.; Denis, S.; Mougin, J.; Guillaneuf, Y.; Lazzari, G.; Zhu, C.; Mura, S.; Couvreur, P.; Nicolas, J. Heterotelechelic polymer prodrug nanoparticles: Adaptability to different drug combinations and influence of the dual functionalization on the cytotoxicity. J. Control. Rel. 2019, 295, 223-236. 
29. Bertrand, N.; Wu, J.; Xu, X.; Kamaly, N.; Farokhzad, O. C. Cancer nanotechnology: the impact of passive and active targeting in the era of modern cancer biology. Adv. Drug Delivery Rev. 2014, 66, 2-25.

30. Mura, S.; Couvreur, P. Nanotheranostics for personalized medicine. Adv. Drug Delivery Rev. 2012, 64, 1394-1416.

31. Lammers, T.; Aime, S.; Hennink, W. E.; Storm, G.; Kiessling, F. Theranostic nanomedicine. Acc. Chem. Res. 2011, 44, 1029-1038.

32. Weissleder, R., A clearer vision for in vivo imaging. Nature Publishing Group: 2001.

33. Smith, A. M.; Mancini, M. C.; Nie, S. Bioimaging: second window for in vivo imaging. Nature Nanotech. 2009, 4, 710.

34. Harrisson, S.; Couvreur, P.; Nicolas, J. Simple and efficient copper metal-mediated synthesis of alkoxyamine initiators. Polym. Chem. 2011, 2, 1859-1865.

35. Benoit, D.; Chaplinski, V.; Braslau, R.; Hawker, C. J. Development of a Universal Alkoxyamine for Living Free Radical Polymerizations. J. Am. Chem. Soc. 1999, 121, 39043920.

36. Benoit, D.; Harth, E.; Fox, P.; Waymouth, R. M.; Hawker, C. J. Accurate Structural Control and Block Formation in the Living Polymerization of 1,3-Dienes by Nitroxide-Mediated Procedures. Macromolecules 2000, 33, 363-370.

37. Fessi, H.; Puisieux, F.; Devissaguet, J. P.; Ammoury, N.; Benita, S. Nanocapsule formation by interfacial polymer deposition following solvent displacement. Int. J. Pharm. 1989, 55, R1-R4.

38. Maksimenko, A.; Mougin, J.; Mura, S.; Sliwinski, E.; Lepeltier, E.; Bourgaux, C.; Lepêtre, S.; Zouhiri, F.; Desmaële, D.; Couvreur, P. Polyisoprenoyl gemcitabine conjugates self assemble as nanoparticles, useful for cancer therapy. Cancer Lett. 2013, 334, 346-353.

39. Mura, S.; Buchy, E.; Askin, G.; Cayre, F.; Mougin, J.; Gouazou, S.; Sobot, D.; Valetti, S.; Stella, B.; Desmaele, D. In vitro investigation of multidrug nanoparticles for combined therapy with gemcitabine and a tyrosine kinase inhibitor: Together is not better. Biochimie 2016, 130, 4-13.

40. Ren, W. X.; Han, J.; Uhm, S.; Jang, Y. J.; Kang, C.; Kim, J.-H.; Kim, J. S. Recent development of biotin conjugation in biological imaging, sensing, and target delivery. Chem. Commun. 2015, 51, 10403-10418.

41. Taheri, A.; Dinarvand, R.; Atyabi, F.; Nouri, F.; Ahadi, F.; Ghahremani, M. H.; Ostad, S. N.; Borougeni, A. T.; Mansoori, P. Targeted delivery of methotrexate to tumor cells using biotin functionalized methotrexate-human serum albumin conjugated nanoparticles. J. Biomed. Nanotechnol. 2011, 7, 743-753.

42. Bui, D. T.; Nicolas, J.; Maksimenko, A.; Desmaële, D.; Couvreur, P. Multifunctional squalene-based prodrug nanoparticles for targeted cancer therapy. Chem. Commun. 2014, 50, 5336-5338. 
43. Mackiewicz, N.; Nicolas, J.; Handké, N. g.; Noiray, M.; Mougin, J.; Daveu, C.; Lakkireddy, H. R.; Bazile, D.; Couvreur, P. Precise engineering of multifunctional PEGylated polyester nanoparticles for cancer cell targeting and imaging. Chem. Mater. 2014, 26, 1834-1847.

44. Russell-Jones, G.; McTavish, K.; McEwan, J.; Rice, J.; Nowotnik, D. Vitamin-mediated targeting as a potential mechanism to increase drug uptake by tumours. J. Inorg. Biochem. 2004, 98, 1625-1633.

45. Pérez-Herrero, E.; Fernández-Medarde, A. Advanced targeted therapies in cancer: Drug nanocarriers, the future of chemotherapy. Eur. J. Pharm. Biopharm. 2015, 93, 52-79.

46. Hong, G.; Antaris, A. L.; Dai, H. Near-infrared fluorophores for biomedical imaging. Nature Biomed. Eng. 2017, 1, 0010.

47. Hertel, L. W.; Boder, G. B.; Kroin, J. S.; Rinzel, S. M.; Poore, G. A.; Todd, G. C.; Grindey, G. B. Evaluation of the antitumor activity of gemcitabine (2', 2'-difluoro-2'-deoxycytidine). Cancer Res. 1990, 50, 4417-4422.

48. Yang, H.-C.; Silverman, J.; Wozniak, J. J. Low temperature heat shrinkable polymer material. US4596728A, 1986.

49. Guillaneuf, Y.; Dufils, P.-E.; Autissier, L.; Rollet, M.; Gigmes, D.; Bertin, D. Radical chain end chemical transformation of SG1-based polystyrenes. Macromolecules 2009, 43, 91-100.

50. Couvreur, P.; Stella, B.; Reddy, L. H.; Hillaireau, H.; Dubernet, C.; Desmaële, D.; LepêtreMouelhi, S.; Rocco, F.; Dereuddre-Bosquet, N.; Clayette, P.; Rosilio, V.; Marsaud, V.; Renoir, J.-M.; Cattel, L. Squalenoyl Nanomedicines as Potential Therapeutics. Nano Lett. 2006, 6, 2544-2548.

51. Kumar, R.; Han, J.; Lim, H.-J.; Ren, W. X.; Lim, J.-Y.; Kim, J.-H.; Kim, J. S. Mitochondrial induced and self-monitored intrinsic apoptosis by antitumor theranostic prodrug: in vivo imaging and precise cancer treatment. J. Am. Chem. Soc. 2014, 136, 17836-17843.

52. Jung, D.; Maiti, S.; Lee, J. H.; Lee, J. H.; Kim, J. S. Rational design of biotin-disulfidecoumarin conjugates: a cancer targeted thiol probe and bioimaging. Chem. Commun. 2014, 50, 3044-3047.

53. Maiti, S.; Park, N.; Han, J. H.; Jeon, H. M.; Lee, J. H.; Bhuniya, S.; Kang, C.; Kim, J. S. Gemcitabine-coumarin-biotin conjugates: a target specific theranostic anticancer prodrug. $J$. Am. Chem. Soc. 2013, 135, 4567-4572.

54. Bhuniya, S.; Maiti, S.; Kim, E. J.; Lee, H.; Sessler, J. L.; Hong, K. S.; Kim, J. S. An activatable theranostic for targeted cancer therapy and imaging. Angew. Chem., Int. Ed. 2014, $126,4558-4563$.

55. Heo, D. N.; Yang, D. H.; Moon, H.-J.; Lee, J. B.; Bae, M. S.; Lee, S. C.; Lee, W. J.; Sun, I.C.; Kwon, I. K. Gold nanoparticles surface-functionalized with paclitaxel drug and biotin receptor as theranostic agents for cancer therapy. Biomaterials 2012, 33, 856-866. 
56. Heinemann, V.; Xu, Y.-Z.; Chubb, S.; Sen, A.; Hertel, L. W.; Grindey, G. B.; Plunkett, W. Cellular elimination of 2', 2'-difluorodeoxycytidine 5'-triphosphate: a mechanism of selfpotentiation. Cancer Res. 1992, 52, 533-539.

57. Szebeni, J.; Muggia, F.; Gabizon, A.; Barenholz, Y. Activation of complement by therapeutic liposomes and other lipid excipient-based therapeutic products: Prediction and prevention. Adv. Drug Delivery Rev. 2011, 63, 1020-1030.

58. Szebeni, J. Complement activation-related pseudoallergy: A stress reaction in blood triggered by nanomedicines and biologicals. Mol. Immunol. 2014, 61, 163-173.

59. Taheri, A.; Dinarvand, R.; Nouri, F. S.; Khorramizadeh, M. R.; Borougeni, A. T.; Mansoori, P.; Atyabi, F. Use of biotin targeted methotrexate-human serum albumin conjugated nanoparticles to enhance methotrexate antitumor efficacy. Int. J. Nanomed. 2011, 6, 1863.

60. Sivak, L.; Subr, V.; Tomala, J.; Rihova, B.; Strohalm, J.; Etrych, T.; Kovar, M. Overcoming multidrug resistance via simultaneous delivery of cytostatic drug and P-glycoprotein inhibitor to cancer cells by HPMA copolymer conjugate. Biomaterials 2017, 115, 65-80.

61. Li, H.; Li, K.; Dai, Y.; Xu, X.; Cao, X.; Zeng, Q.; He, H.; Pang, L.; Liang, J.; Chen, X. In vivo near infrared fluorescence imaging and dynamic quantification of pancreatic metastatic tumors using folic acid conjugated biodegradable mesoporous silica nanoparticles. Nanomedicine: NBM 2018, 14, 1867-1877.

62. Xu, H.; Bandari, R. P.; Lee, L.; Li, R.; Yu, P.; Smith, C. J.; Ma, L. Design, Synthesis, and in Vitro and in Vivo Evaluation of High Affinity and Specificity Near-Infrared Fluorescent Bombesin Antagonists for Tumor Imaging. J. Med. Chem. 2018, 61, 7657-7670.

63. Zhang, Y.-N.; Poon, W.; Tavares, A. J.; McGilvray, I. D.; Chan, W. C. Nanoparticle-liver interactions: Cellular uptake and hepatobiliary elimination. J. Control. Rel. 2016, 240, 332348.

\section{Graphical abstract}

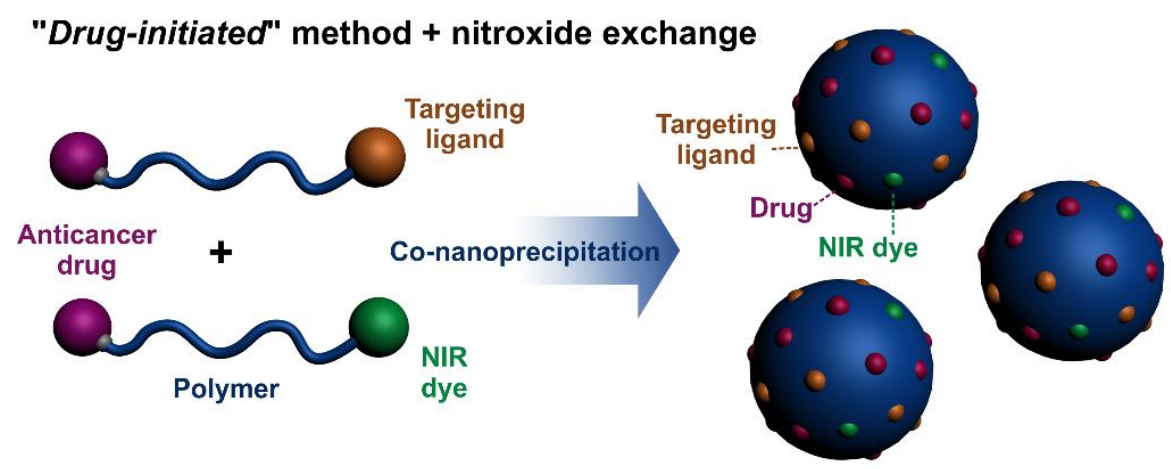

